\title{
ÉTICA Y ECONOMÍA: LA DIMENSIÓN HUMANA $(\eta)^{*}$
}

GERARDO SILVA VEGAS**

E-mail: gsilvavlesan.org.pe

\section{RESUMEN}

La pregunta sobre cuál es la dimensión humana encierra una gran complejidad; sin embargo, la modernidad pretende responderla de una manera simplona desde una lógica del Tener. Es decir, el hombre es medido por el nivel de sus ingresos.

La búsqueda de nuevas formas de abordar la medición del hombre permite redescubrir, en la concepción de acto y potencia de Aristóteles y su actualización en la teoría de las capacidades humanas de Amartya Sen, un enfoque diferente que brinda una respuesta mucho más profunda desde una lògica del Ser. No obstante, medir la capacidad humana es sumamente difícil porque es un intangible.

Esta investigación pretende, desde la idea hegeliana de la objetivación de la subjetividad por el trabajo, proponer un punto de partida para allanar la dificultad, complementándola con la clasificación de las necesidades de A. Maslow.

Palabras clave: Dimensión humana, tener, ser.

\section{ABSTRACT}

The question of what the human dimension is, contains a great complexity, however, the modernity tries to respond in a simple way from a logic of having, that is to say, the man is measured by the level of his revenues.

The search of new ways to know human's dimension, allows to rediscover him in Aristotle's act conception and its updating in Amartya Sen's human capacities theory, a different focus that offers a much deeper answer from a being's logical point of view. Nevertheless, to measure the human capacity is extremely difficult because it is an intangible one. This research is looking for the Hegelian idea of the objectivity, of the subjectivity for work, a starting point to level the difficulty and complement it with the classification of Abraham Maslow's needs.

Keywords: Human dimension, having, being.

* El presente artículo ha sido elaborado tomando como base la investigación desarrollada el año 2003 para optar el grado de Magíster en Economía en la Universidad Católica del Perú con la tesis «Ciencia y Filosofía: el caso de la ciencia económica». Versión completa del artículo en proceso de publicación por la Facultad de Letras y Ciencias Humanas de la Universidad Nacional Mayor de San Marcos.

* Magíster en Administración y Finanzas por ESAN y docente de la Universidad Nacional Mayor de San Marcos. 


\section{INTRODUCCIÓN}

Observemos nuestro tiempo y nuestro espacio, detengámonos un momento a ver la situación económica y social de nosotros mismos, de nuestra familia, de nuestro barrio. Caminemos por las calles de nuestra ciudad o por los caminos de nuestro país; informémonos sobre la situación de América Latina, de África al Sur del Sahara, de Asia Meridional, o la situación de la humanidad en general, y notaremos que cualquiera que sea el ámbito de tiempo y espacio, nuestra sensibilidad se verá conmovida por algún aspecto de la vida de los seres humanos con los que compartimos el planeta. Nuestra conciencia personal nos impulsaría, entonces, a asumir alguna responsabilidad.

Habrá quienes, como Martha Nussbaum, se preguntarán si tendremos esa capacidad de afiliación que nos impulse a vivir para y hacia otros; reconociendo y mostrando preocupación por otros seres humanos; comprometidos en las múltiples formas de interacción social; imaginando la situación del otro y teniendo compasión por ella; con capacidad para la justicia y la amistad, defendiendo la institucionalidad de las formas de afiliación, las libertades de asamblea y de discurso político. Habrá también quienes, por el contrario, eludirán cualquier responsabilidad en la situación de nuestro tiempo y nuestro espacio.

La realidad de la vida de los seres humanos en el ámbito local o global es grave: las estadísticas económicas del Banco Mundial (World Development Reports 2000/2001), del PNUD (Informe sobre desarrollo humano 1998), o de CEPAL (Panorama social de América Latina y el Caribe 2002-2003), nos muestran la creciente gravedad de la situación económica del mundo y, en especial, de América Latina; las evidencias nos muestran que vivimos en el continente más desigual y que en nuestra región la cantidad de pobres se ha duplicado en las últimas tres décadas.

Los puntos de diferencia entre el ingreso per cápita de los países más ricos y el de los más pobres pasó de once en 1870, a treinta y ocho en 1960 y a cincuenta y dos en 1985; la velocidad de crecimiento económico de los países más ricos es ascendente. Así, quienes van adelante en la carrera del «progreso» corren más y más rápido, y la brecha entre los países del norte y los del sur es cada vez mayor, como lo señala Javier Iguiñiz en su ponencia «Ética y Desarro110: enfoques y realidad mundial y latinoamericana», presentada en el «III Simposio Ética, política y economía: Entre la globalización y la pobreza» realizado en Quito en setiembre de 2004 .

Según datos del PNUD (1998):

- Las tres personas más ricas tienen activos que superan el PBI combinado de los cuarenta y ocho países menos adelantados.

- Las quince personas más ricas tienen activos que superan el PBI total del África al Sur del Sahara.

- La riqueza de las treinta y dos personas más ricas supera el PBI total del Asia Meridional.

- Si queremos lograr y mantener que todos tengan acceso a la enseñanza básica, atención básica de salud y específicamente de salud reproductiva para las mujeres, alimentación suficiente, agua limpia y saneamiento, se estima que son necesarios 44000 millones de dólares al año, aproximadamente. Esto es inferior al 4\% de la riqueza combinada de las 225 personas más ricas del mundo.

- Actualmente la riqueza neta de las diez personas más opulentas es de 133000 millones de dólares, 1.5 veces mayor que el ingreso nacional conjunto de todos los países menos adelantados.

Javier Iguiñiz explica en su ponencia cómo en nuestro continente la «pobreza de ingreso» ha aumentado hasta el punto de duplicarse en los últimos treinta años. Así, según datos de CEPAL, en 1960 existían 110 millones de pobres en América Latina y en 1990 llegaron a 200 millones. Para el 2002 la cifra se estimó en 221.4 millones y para el siguiente año fueron 226.6 millones. Sobre la distribución del ingreso Iguiñez, nos señala cómo el coeficiente Gini de América Latina es mucho mayor que en otros grupos de países como el África Subsahariana, el Medio Oriente, el Norte de África, el Asia Oriental y Meridional, la Europa del Este y los países en desarrollo de mayores ingresos. Por ejemplo, la riqueza del mexicano más rico ascendía en 1995 a 6600 millones de dólares, igual al ingreso combinado de los 17 millones de mexicanos más pobres.

Esta dramática pobreza en América Latina nos conmueve y suscita este artículo, nos responsabiliza en el reclamo y la acción por el 
derecho a existir como sociedad y como cultura. La pobreza amenaza nuestra existencia, por ello, los versos de Parménides sobre la naturaleza del Ser adquieren para nosotros un nuevo significado, un sentido muy singular: el derecho a existir (Lo que es, es y no es posible no ser).

Sentimos que nuestra existencia se encuentra amenazada, la pobreza absoluta que nos envuelve y amenaza nuestro futuro como Ser. Sin embargo, estos fragmentos de Parménides también nos llenan de esperanza porque nos dicen:

\section{... no es posible no ser}

Queremos leer esa imposibilidad del no ser en un sentido deontológico: no es posible que nos nieguen la existencia, debemos negar esa posibilidad.

¿Cuáles son las dos vías de búsqueda que pueden pensarse? La una: es y no es posible que no sea.

Ésta es la vía digna de fe (pues la verdad la acompaña). Mas la otra: no es y que el no ser es necesario.

Éste por cierto te hago saber es un sendero en el que no cabe aprender nada.

Pues no puedes ni concebir lo que no es, pues ello no es posible ni expresarlo.

No hay derecho en que pretendan negar la existencia, no podemos concebirlo. Pero lamentablemente es así. Desde el fin de la Segunda Guerra Mundial las potencias vencedoras organizaron su hegemonía y crearon las instituciones necesarias para ejercerla. Surgieron, así, entre otros organismos mundiales, el Banco Mundial, el Fondo Monetario Internacional (FMI) y la Organización Mundial de Comercio (OMC), como parte de una nueva institucionalidad global política y económica. Las políticas económicas desarrolladas por estas instituciones han tenido como objetivo, según sus propias declaraciones, «el combate a la pobreza» en países como el nuestro. Pero observamos que más de medio siglo después, la situación se ha agravado. Los resultados de estas políticas se pueden apreciar en los informes del Banco Mundial, el PNUD o CEPAL; más aún, en la última década en América Latina se ha aplicado de manera ortodoxa el modelo económico neoclásico. Tanto el Perú de Fujimori como la Argentina de Menen siguieron al pie de la letra las recomendaciones de política económica del Fondo, y los
Artículo: A pesar de los avances, millones de personas siguen en la extrema pobreza

Número de personas que viven con menos de US \$ 1 diarios (en millones)

\begin{tabular}{|c|c|c|c|}
\hline Región & 1990 & 1999 & 2015 \\
\hline Asia Oriental y el Pacífico & 452 & 260 & 59 \\
\hline (Excluye China) & 92 & 46 & 6 \\
\hline Europa y Asia Central & 7 & 17 & 4 \\
\hline $\begin{array}{l}\text { América Latina y el } \\
\text { Caribe }\end{array}$ & 74 & 77 & 60 \\
\hline $\begin{array}{l}\text { Medio Oriente y África } \\
\text { Septentrional }\end{array}$ & 6 & 7 & 6 \\
\hline Asia del Sur & 495 & 490 & 279 \\
\hline África al Sur del Sahara & 242 & 300 & 345 \\
\hline $\begin{array}{l}\text { Total } \\
\text { (excluye China) }\end{array}$ & $\begin{array}{c}1276 \\
916\end{array}$ & $\begin{array}{r}1151 \\
936\end{array}$ & $\begin{array}{l}753 \\
700\end{array}$ \\
\hline $\begin{array}{l}\text { Fuente: } \\
\text { http://Inweb18.worldbe } \\
\text { chments/pr042002-es }\end{array}$ & e/pro & 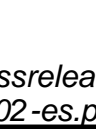 & Atta \\
\hline
\end{tabular}

resultados son los que estamos viviendo en este momento.

Los cuadros que nos presenta el Banco Mundial señalan que hay millones de «personas que viven con menos de US\$ 1 diario», ello supone la comparación con aquellos que viven con más de US\$ 1 diario. Quedarnos en esa lógica comparativa supondría aceptar que es un problema entre los que tienen menos de un dólar y los que tienen más de un dólar. Aparentemente se trataría de un problema de redistribución del ingreso y de pobreza relativa, que podría enfrentarse con «ayuda internacional».

\subsection{LA GRAVEDAD DE LA POBREZA ABSOLU- TA: LA EXCLUSIÓN ECONÓMICA}

No obstante todas las referencias estadísticas de pobreza relativa que hemos presentado en las líneas anteriores, creemos que esos cuadros expresan un problema mucho más grave: muestran una situación de pobreza absoluta, aunque ello no sea evidente. No se trata, pues, de compararnos con aquellos que tienen más, la comparación no es con otros, sino con nosotros mismos, la comparación es con lo necesario para reproducir nuestra propia existencia. Precisamente, en América Latina, en África y en Asia, la existencia de esos millones de personas se encuentra amenazada por esa exclusión económica que impide la recreación del propio Ser. Además, habría 
que preguntarse si esa cifra arbitraria de US\$ 1 tiene alguna relación con lo necesario para la reproducción de la vida humana; habría que preguntarse si es una buena unidad de medida de la pobreza.

Pareciera que la economía solamente trata sobre la producción y distribución de bienes:

"Independientemente de cómo se organice una sociedad para la actividad de producción y distribución de bienes, hay ciertas relaciones que se establecen entre los elementos materiales y no materiales que intervienen en la producción. Estas son las relaciones tecnológicas» (Figueroa, 1996:35).

«La economía es una ciencia, una ciencia social. Estudia un proceso particular: el proceso económico....».

«Este es definido como el proceso de producción de bienes y su distribución entre los distintos grupos sociales que forman las sociedades humanas» ${ }^{3}$.

\section{LAS CAPACIDADES HUMANAS EN EL SENTIDO DE AMARTYA SEN}

Hace 20 años tuvimos oportunidad de conocer, gracias a las enseñanzas del profesor Iguiñiz, las primeras publicaciones de Sen, cuando todavía nadie imaginaba que iba a convertirse en un Premio Nobel de Economía. En ese entonces no comprendimos en toda su profundidad el significado de la palabra capacidad.

Ahora, el enfoque de este artículo, tomando esa teoría de capacidades, pretende abordar el problema de la pobreza más allá de cuestiones redistributivas del ingreso o cuestiones de explotación. Cuando la carencia de bienes y la exclusión del trabajo pone en peligro la existencia misma de los hombres estamos hablando de pobreza absoluta. Ya no se trata de que unos tengan más que otros, o de que esos unos se apropien del excedente social, el problema es que tenemos tan poco que ya no podemos reproducir nuestra existencia y, además, estamos excluidos por el sistema social de la posibilidad de salir de esa situación.

El profesor Sen es el autor que nos ha llevado a redescubrir, desde la Economía, el antiguo pensamiento aristotélico; nos ha introducido a un nuevo concepto de capacidades con un matiz propio: la libertad.

"In this paper I have outlined and defended an interpretation of positive freedoms. The interpretation sees freedoms in the form of particular capabilities...».

«Capabilities are -as I have argued- directly valuable in a way that the possession of primary goods cannot be, since they evidently are means to some more human ends...».

«Concern with positive freedoms leads directly to valuing people's capabilities and instrumentally to valuing things that enhance these capabilities. The notion of capabilities relates closely to the functioning of a person. This has to be contrasted with the ownership of goods, the characteristics of goods owned, and the utilities generated ${ }^{4}$.

La diferenciación entre las capacidades humanas y la posesión de bienes nos lleva a una diferenciación entre lo que es esencial a la naturaleza humana y lo que es accidental (en un sentido aristotélico de los términos) y nos permite, usando adecuadamente los medios, movernos desde 10 esencial hacia el cumplimiento de los fines del hombre y hacia la ampliación de sus capacidades. La noción de capacidad está estrechamente relacionada con el concepto mismo de hombre, de su funcionamiento como tal, de aquello que lo hace ser.

Conquistar la libertad para ser uno mismo y desarrollarse en la dirección de su elección, aumentando las capacidades que uno mismo valore más como persona y como ser social. Los bienes, así entendidos, constituyen los medios o instrumentos para la consecución de los fines humanos. El desarrollo de las capacidades humanas es la forma en que el hombre amplía sus propias potencias; por el contrario, poner como finalidad a los bienes nos aleja de los fines propiamente humanos.

La pobreza, la incapacidad de Ser, la falta de libertad para recorrer el camino hacia la realización plena (entelecia) de nuestra existencia, fue lo que nos impulsó, de la mano del profesor Sen, a comenzar esta investigación. La capacidad para aparecer en público sin sonrojarse:

«La idea de que la pobreza no es más que la escasez de renta está bastante arraigada en la literatura sobre el tema. No es una idea absurda, ya que la renta-debidamente definida-influye mucho en lo 
que podemos o no podemos hacer».

"La falta de renta suele ser la principal causa de las privaciones que relacionamos con la pobreza, incluida la inanición y las hambrunas. También existen, sin embargo, buenas razones para no terminar con un análisis de la renta exclusivamente... Centrar la atención en la vida real que consiguen los individuos, o yendo más allá, en la libertad para conseguir la vida real que podemos tener razones para valorar».

«El interés por la vida real de los individuos no es algo nuevo en economía. De hecho, la descripción aristotélica del bien humano estaba relacionada explícitamente con la necesidad de 'averiguar primero la función del hombre' y después explorar 'la vida en el sentido de actividad' como elemento básico del análisis normativo».

«.. la capacidad para aparecer en público sin sonrojarse o para participar en la vida de la comunidads ${ }^{5}$.

Recordando los conceptos de potencia (dýnamis, $\delta \psi v \alpha \mu 1 \sigma$ ), acto (energía, enérgeia,

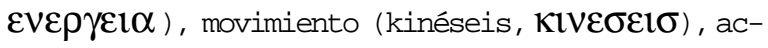
ción (práxeis, $\pi \rho \alpha \xi \varepsilon l \sigma)$, plena realización (entelequia, enteléchia, $\varepsilon V \tau \varepsilon \lambda \varepsilon \chi(\alpha)$ de la Metafísica de Aristóteles, esta cita de Sen adquiere significados más profundos. Al relacionar los conceptos de 'vida real', 'función del hombre', 'sentido de actividad' y 'capacidad' con los anteriores, entendemos la profundidad de la referencia aristotélica.

«...las tenencias de bienes pueden suministrarnos en realidad bastante poca información sobre la naturaleza de la vida que pueden llevar los respectivos individuos. Las rentas reales son, pues, unos indicadores bastante insatisfactorios de importantes componentes del bienestar y de la calidad de vida que los individuos tienen razones para valorar».

«La pobreza debe concebirse como la privación de capacidades básicas y no meramente como la falta de ingresos.... ${ }^{6}$.

El reducir el estudio de la pobreza y la economía a una simple cuestión de renta, no nos permite entender la cuestión de la pobreza, ni el significado de la 'vida real', ni el 'sentido de la actividad' y menos aún la plena realización (entelequia, enteléchia, $\varepsilon v \tau \varepsilon \lambda \varepsilon \chi 1 \alpha$ ). La definición de la pobreza como 'privación de las capacidades' nos introduce al verdadero significado de 'capacidad' o 'potencia' para Amartya Sen. El enfoque de capacidades de Amartya Sen nos devuelve al verdadero sentido ético de la economía y nos regresa a la verdadera búsque- da de la realización de los fines humanos en su actividad económica.

Aparecer en público sin sonrojarse, en nuestro país, es una cuestión que afecta a muchísimos; la pobreza mella nuestra autoestima. ¿Cuál es nuestra propia naturaleza, cuáles son las capacidades que poseemos? Sin embargo, nos vemos excluidos, no podemos poner en acto nuestras capacidades, entonces, la dignidad menoscabada por la desocupación nos sonroja al aparecer en público.

\subsection{LA POTENCIA EN EL SENTIDO ARISTOTÉLICO}

El concepto de capacidad en Amartya Sen es más complejo que el concepto de potencia en la Física moderna. Ambos tienen su antecedente en la idea aristotélica de potencia, aunque el significado de este concepto es mucho más amplio en el Estagirita que en la ciencia física, va mucho más allá de un concepto estrictamente mecánico, asociado a la causa eficiente; el significado de movimiento es indesligable de su Ser, de su ontología y de su telos. El concepto aristotélico de potencia sustenta filosóficamente el concepto de capacidades de Sen.

En el capítulo duodécimo del Libro $\mathrm{V}$ de $\mathrm{la}$ Metafísica, Aristóteles nos define lo que entiende por potencia, como veremos, el significado tiene un carácter fundamentalmente cualitativo, antes que cuantitativo.

«[1] Se llama potencia o capacidad

(a) el principio del movimiento o del cambio que se da en otro, o bien 'en lo mismo que es cambiado, pero' en tanto que otro...

En general, pues, se llama potencia o capacidad: de una parte, el principio del cambio o del movimiento que se da en otro, o bien 'en lo mismo que es cambiado, pero' en tanto que otro.

De otra parte, 'el principio según el cual algo es cambiado o movido' por la acción de otro, o bien 'de ello mismo, pero' en tanto que otro»'

Esta primera definición de potencia, según el estagirita, nos introduce al principio causal del movimiento: lo que se mueve es movido por otro, y para no llegar al absurdo de una cadena infinita de causalidades, esta cadena causal la resuelve en el Motor Inmóvil de su teología, lo que mueve sin ser movido. 
El movimiento tiene un sentido mucho más amplio que el simple movimiento mecánico de traslación de un lugar a otro. Aquí movimiento tiene un sentido de cambio de calidad y de cantidad, de generación y degeneración, de camino hacia la transformación del ente en entelequia, hacia lo que alcanza su finalidad. Este último significado, el movimiento hacia la realización plena, hacia la entelequia, lo que Aristóteles llama el movimiento perfecto, tiene especial importancia en esta investigación, en la que nos preguntamos sobre el telos de la actividad económica del hombre.

La concepción aristotélica del movimiento es indesligable de su concepción de los cuatro principios causales:

- la causa material,

- la causa formal,

- la causa eficiente y

- la causa final.

La reducción del estudio del movimiento a una perspectiva restringida a la causa eficiente, actitud propia de la ciencia moderna y en especial de la Física, tiene la implicancia que nos aleja de la finalidad de la acción y nos reduce a una racionalidad únicamente instrumental en función de los medios y la técnica, perdiendo el sentido ético de esta acción, su sentido teleológico.

Otro significado de potencia es el siguiente:

«(b). Además, la capacidad de realizar algo perfectamente, o según la propia intención...»

Potencia también es entendida como libertad para elegir según la propia intención, aspecto que adquirirá, como veremos más adelante, relevancia especial en la concepción de potencia de Amartya Sen.

Luego, en el libro IX de Metafísica, Aristóteles se ocupa de los sentidos del ser como ser en potencia y ser en acto, desarrollando lo fundamental de los conceptos de potencia y acto. Revisemos, pues, las siguientes citas:

«...si lo que está privado de potencia es incapaz, lo que no se ha generado será incapaz de generarse... es evidente que potencia (dýnamis, Suvoqua y acto (energía, enérgeia, evepjelo) son distintos y, por tanto, cabe que algo pueda ser, pero no sea, y pueda no ser, pero sea...»

«La palabra 'acto', vinculada a la realización plena (entelequia, enteléchia, evE्(EX) también a otras cosas, funda-mentalmente a partir de los movimientos».
«En efecto, parece que el acto es, fundamentalmente, el movimiento» ${ }^{8}$.

El acto vinculado a la entelequia, nos lleva a una importante distinción entre movimiento

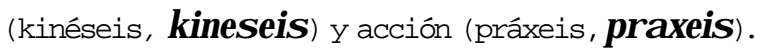
Los movimientos son entendidos como imperfectos porque continúan en su actualización, en cambio, la acción es entendida como algo perfecto, sólo termina cuando alcanza su fin (telos, $\tau \varepsilon \lambda \circ \sigma)$.

Esta distinción entre movimiento y acción nos ayuda en la comprensión de esa pérdida de sentido en la actividad económica del hombre, cuando se llega a la irracionalidad de la exclusión de unos hombres por otros, con la consecuencia de pobreza absoluta y conduce a la negación del $\tau \varepsilon \lambda \circ \sigma$ económico, como hemos señalado antes.

«... está en movimiento en cuanto que aún no se da aquello para lo cual es el movimiento, ninguna de ellas es propiamente acción o, al menos, no es acción perfecta (ya que no es el fin). En ésta, por el contrario, se da el fin y la acción...»

«Asi, por ejemplo, uno sigue viendo 'cuando ya ha visto', y medita 'cuando ya ha meditado' $y$ piensa cuando ya ha pensado, pero no sigue aprendiendo cuando ya ha aprendido, no sigue sanando cuando ya ha sanado... Pues bien, de ellos los unos han de denominarse movimientos $y$ los otros, actos».

«Y es que todo movimiento es imperfecto...» 9

La potencia nos conduce al acto, sin embargo, cuando este acto se constituye como movimiento imperfecto, los medios, la técnica, la tecnología adquieren relevancia especial y pretenden llenar el vacío dejado por la ausencia del fin. Por el contrario, cuando el acto se orienta en la dirección de su principio final, entonces, logra su realización plena, se hace entelequia.

Luego, en el capítulo octavo nos plantea la anterioridad del acto respecto a la potencia:

«Pero lo es también en cuanto a la entidad [acto anterior a potencia]

[1] En primer lugar, porque las cosas que son posteriores en cuanto a la generación son anteriores en cuanto a la forma específica, es decir, en cuanto a la entidad... y porque todo lo que se genera progresa hacia un principio, es decir, hacia un fin... y el acto es fin, y la potencia se considera tal en función de él...» 
«Además, la materia es en potencia en cuanto que puede alcanzar la forma específica, y una vez que está en acto, está ya en la forma específica...»

«La actuación es, en efecto, el fin, y el acto es la actuación, y por ello la palabra 'acto' (enérgeia, $\varepsilon v \varepsilon \rho \gamma \varepsilon 1 \alpha$ ) se relaciona con 'actuación' (érgon, Epyov) y tiende a la plena realización (entelequia,

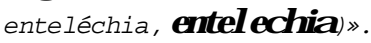

«[2] Pero es anterior en un sentido más fundamental. $Y$ es que las cosas eternas son, en cuanto a la entidad, anteriores a las cosas corruptibles, y nada que es en potencia es eterno» ${ }^{10}$.

La precedencia del acto respecto a la potencia, según Aristóteles, nos lleva a proponer, desde nuestra propia perspectiva, que es propiamente el acto humano, el trabajo, lo que históricamente ha elevado las potencias de la humanidad, en un crecimiento potencial que implica calidades superiores y no solamente un incremento de cantidades.

\section{LA DIMENSIÓN HUMANA $(\eta)$ : LA POTENCIA, EL CAPITAL HUMANO ACUMULABLE}

El enfoque económico de capacidades de Amartya Sen nos lleva más allá de la simple tenencia de bienes y las rentas reales. El enfoque económico tradicional es bastante limitado para comprender las profundidades de la naturaleza de la vida humana, sus mediciones son insatisfactorias para expresar importantes componentes del bienestar y la calidad de vida que las personas o colectividades tienen razones para valorar.

Esta búsqueda nos llevó a la formulación de un modelo económico diferente al desarrollado por la economía neoclásica, tomando como aspecto central el trabajo humano; de esta manera, los bienes son tomados como un insumo del proceso productivo de capacidades humanas. Entonces, la recreación ampliada del hombre fue el resultado final del modelo explicado en la investigación «Filosofía y Ciencia: El caso de la ciencia económica», sin embargo, en este artículo prescindimos del desarrollo matemático del modelo económico y solamente presentaremos sus conclusiones: la reproducción ampliada de $\mathbf{H}$.

La dimensión humana está en función de las variables trabajo y bienes de capital:

\begin{tabular}{|ll|}
\hline$H$ & $f x, T$ \\
$\mathrm{H}$ & El Ser del Hombre \\
$\mathrm{X}$ & Bienes \\
$\mathrm{T}$ & Trabajo \\
\hline
\end{tabular}

\begin{tabular}{|ll|}
$H$ & $H_{n} \quad H_{e}$ \\
$\mathrm{H}_{\mathrm{n}}$ & Lo que es \\
$\mathrm{H}_{\mathrm{e}}$ & Qué es \\
\hline
\end{tabular}

Surge entonces la pregunta: ¿qué es H?, ¿qué es el hombre?

La respuesta sería inagotable, hiperbólica, solo se resolvería en el infinito. Tenemos que restringir la respuesta al ámbito económico y desde ahí extendernos a otros ámbitos sin perder la perspectiva económica. Analicemos, entonces, el significado de $\mathbf{H}$ en función de bienes y trabajo, así, podemos observar que en el proceso productivo de $\mathbf{н}$ se insume bienes y trabajo humano, у que $\mathbf{H}$ es directamente proporcional a la cantidad de estos. Además, después de cada ciclo productivo tenemos un excedente acumulable de $\mathbf{H}$, que nosotros llamamos $\mathbf{H}_{\mathbf{e}^{\prime}}$ es decir, hemos acumulado una calidad superior de sociedad.

Insisto, una calidad superior y no una cantidad mayor, porque suponemos que el número de hombres es el mismo, sin embargo, después del ciclo productivo la capacidad de esos hombres se ha incrementado y acumulado.

Esa mayor capacidad humana, ese incremento de la potencia del hombre, puede ser entendido como proceso de capitalización, como proceso de acumulación de capital humano.

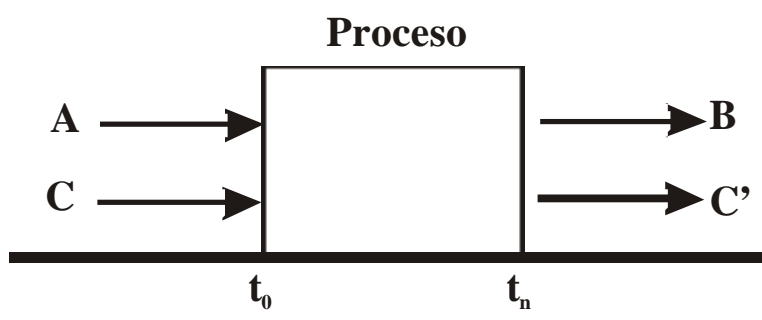

Siguiendo a Georgescu-Roegen y al Dr. Adolfo Figueroa presentamos en la investigación «Filosofía y Ciencia: El caso de la ciencia económica» el diagrama del proceso de producción con los flujos y fondos que intervienen en este.

¿Qué hay de nuevo en nuestra presentación? Lo nuevo es el proceso productivo de $\mathbf{H}$ у la acumulación de capital humano. Por ello, de- 
bemos encontrar en un análisis dimensional aquello que los hombres, en su actividad económica, tienen en común. Tenemos que resolver la cuestión de la unidad en la multiplicidad, así como otras teorías económicas encuentran algún aspecto que resuelve desde su perspectiva particular esta cuestión. Escoger el aspecto de unidad no es simplemente una cuestión analítica y metódica, supone una concepción y una voluntad subyacente.

Nosotros suponemos que ese elemento de unidad es la potencia o capacidad humana. Veamos en el desarrollo de la idea qué implicancias tiene este planteamiento.

\subsection{LA POTENCIA: UNIDAD EN LA MULTIPLI- CIDAD DE H}

La multiplicidad de las capacidades humanas es infinita: podemos hacer esfuerzos por clasificarlas, agrupándolas en conjuntos que guarden alguna afinidad; sin embargo, seguiremos navegando en un mar de multiplicidad. La naturaleza humana se manifiesta en la realidad de esa forma compleja y diversa; lo concreto de esa manifestación fenoménica es la multiplicidad de sus formas.

Lo observable es el fenómeno y en ello está lo concreto de la realidad que se manifiesta en su diversidad como:

- Capacidad fisiológica

- Capacidad de seguridad y regularidad

- Capacidad relacional

- Capacidad de autovaloración y reconocimiento

- Capacidad cognitiva

- Capacidad estética

- Capacidad de realización plena

Históricamente podemos observar los frutos de estas capacidades cuando se ponen en acto. Las sociedades humanas han acumulado capacidades a lo largo de toda su historia. Cada ciclo histórico produce una mayor capacidad del hombre.

Tomemos, como ejemplo, solamente una de ellas, tal vez la más evidente: la capacidad cognitiva. El saber acumulado por la humanidad es hoy tan grande que parecen insignificantes los descubrimientos del pasado. Así, podríamos analizar cada una de las diversas capacidades del hombre en la profundidad debida.

No obstante, este esfuerzo de observación empírica ayudará poco a la comprensión de la dimensión H. Tenemos, necesariamente, que hacer una abstracción de la multiplicidad concreta estableciendo una forma simple que reúna la diversidad en la unidad.

Nos parece que el planteamiento aristotélico sobre el acto y la potencia recogido por Amartya Sen y Martha Nussbaum es una forma clara y distinta de definir la dimensión $\mathbf{H}$ como capacidad o potencia.

«El trabajo es el acto y la potencia es la capacidad de actuar».

«.. la materia es en potencia en cuanto que puede alcanzar la forma específica, y una vez que está en acto, está ya en la forma específica...».

«La actuación es, en efecto, el fin, y el acto es la actuación, y por ello la palabra 'acto' (enérgeia,

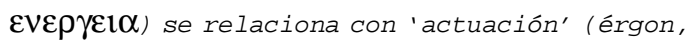

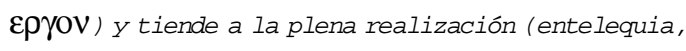
enteléchia, $\varepsilon v \tau \varepsilon \lambda \varepsilon \chi \eta(\alpha){ }^{11}$.

Nosotros acumulamos la capacidad de actuar en el proceso histórico del ciclo de producción, el $\tau \varepsilon \lambda$ o $\sigma$ de la economía se alcanzará en ese movimiento infinito hacia la realización plena del hombre (entelequia, entelechia, $\varepsilon \nu \tau \varepsilon \lambda \varepsilon \chi \eta(\alpha)$.

El concepto potencia expresa de manera unitaria, simple y abstracta la realidad múltiple, compleja y concreta de todas las capacidades humanas.

\section{LA POTENCIA EN LA COMPLEJIDAD DE SUS MÚLTIPLES SIGNIFICADOS}

Nosotros, cuando proponemos la dimensión potencia como unidad de $\mathbf{H}$, pretendemos recoger en su concepto aspectos tan disímiles como aquellos que van desde la tangibilidad de los bienes materiales hasta la intangibilidad de las formas de conciencia, todos ellos como «fruto» de la potencia del hombre en su proceso productivo y todos ellos, también, como «alimento» que la restablece y la amplía en su proceso de consumo.

\subsection{LA POTENCIA EN SU SIGNIFICADO TERMO- D I NÁM I C O}

Tomemos, como primer paso, solo un aspecto del complejo significado de $\mathrm{H}$, esa unidad llamada potencia. Tomemos el aspecto que, empíricamente, es el más fácil de observar: la 
manifestación de los cuerpos en su movimiento, con las transferencias energéticas que ese movimiento implica y el trabajo que genera.

\subsubsection{La potencia: recuperación y ampliación de capacidades}

Veámoslo, pues, en el sentido de la Física: la ley de la conservación de la energía afirma que ésta no puede crearse ni destruirse; así, para proporcionar energía potencial a un sistema es necesario realizar un trabajo. La cantidad de energía transferida a un sistema en forma de calor más la cantidad de energía transferida en forma de trabajo, permiten aumentar la energía potencial del sistema.

Si observamos una esfera cayendo en un estanque veremos que la energía potencial de ésta se transforma en trabajo, alterando la quietud del estanque en la forma de la energía cinética de las ondas. Igualmente, para devolverle la energía potencial que poseía, será necesario realizar un trabajo para elevar la esfera a la altura que tenía antes de caer al estanque.

De manera similar, la puesta en acto de las capacidades humanas permite la transformación de esta energía potencial del hombre en trabajo, y como hemos visto en el modelo del proceso económico, este trabajo se transforma en bienes, que luego, al ser consumidos, le restituyen la energía gastada o la amplían. Para poder graficar esta idea, asumiremos como símbolo de la potencia a la esfera gris y la ubicaremos a una altura graficada en el eje vertical llamado $\mathbf{H}$, como expresión de las unidades de potencia acumulada en el momento inicial. Al ponerse en acto, es decir, al trabajar produce bienes, asumiremos como símbolo de los bienes los cuadrados en gris, que al aumentar se expresarán como cantidad $\left(\mathbf{Q}_{\mathbf{B}}\right)$ a lo largo del eje horizontalB.

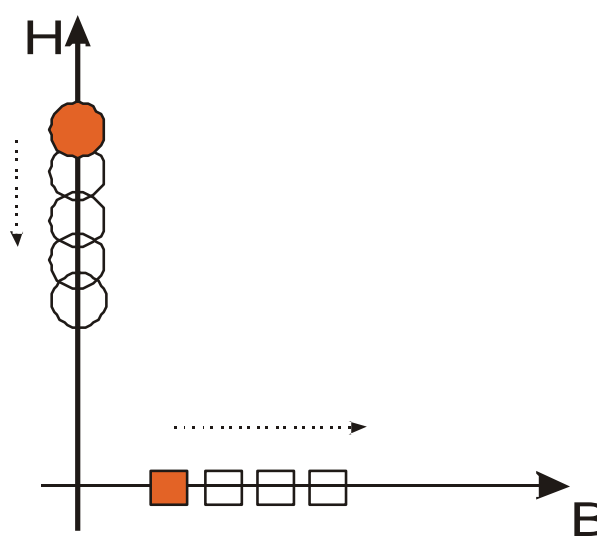

La potencia humana, representada por la esfera gris, al ponerse en acto genera trabajo, representado por el descenso de la esfera desde lo alto del eje vertical H. El efecto del trabajo es la producción de bienes, representado por el cuadrado en gris, y el incremento de la cantidad de bienes $\left(\boldsymbol{Q}_{\mathbf{B}}\right)$, como fruto del trabajo, lo representamos por el desplazamiento del cuadrado a lo largo del eje $\mathbf{B}$.

Tenemos, entonces, una función de producción:

La cantidad de bienes $\left(\mathbf{Q}_{\mathrm{B}}\right)$ está en función de la potencia (H)

$$
Q_{B}=\phi(H)
$$

Ahora, debemos analizar la siguiente fase del proceso económico: el proceso de consumo. Sin embargo, para simplificar, asumamos solo el aspecto biológico de las capacidades humanas. Entonces, la energía potencial biológica del hombre, que antes se consumió productivamente transformándose en trabajo y que se materializó en bienes después y de igual manera pero en sentido inverso, se recupera al nivel original en el acto de consumo «alimentario» de los mismos bienes.

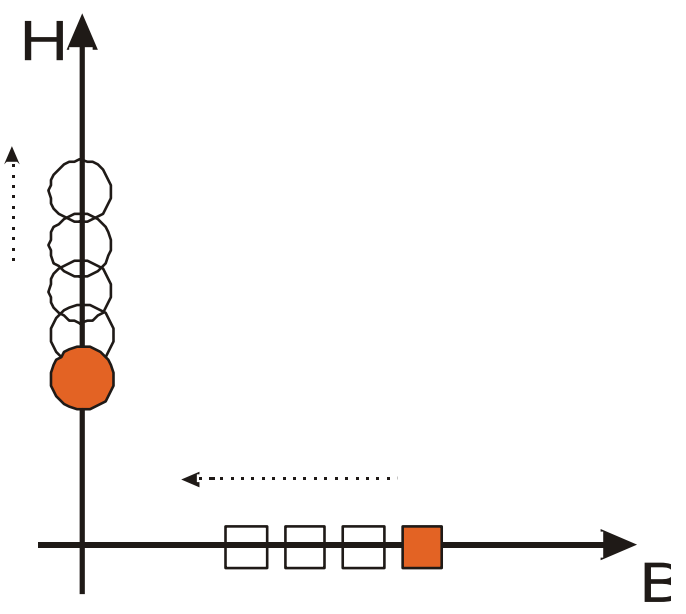

Tenemos, entonces, una función de consumo:

La potencia (H) está en función de la cantidad de bienes $\left(\boldsymbol{Q}_{\mathbf{B}}\right)$, en el sentido biológico de reposición de energías consumidas.

$$
H=\phi\left(Q_{B}\right)
$$

De esta manera, la primera ley de la termodinámica se cumple en estas transferencias recíprocas de calor y trabajo a lo largo del eje $\mathrm{H}$ y del eje B. 


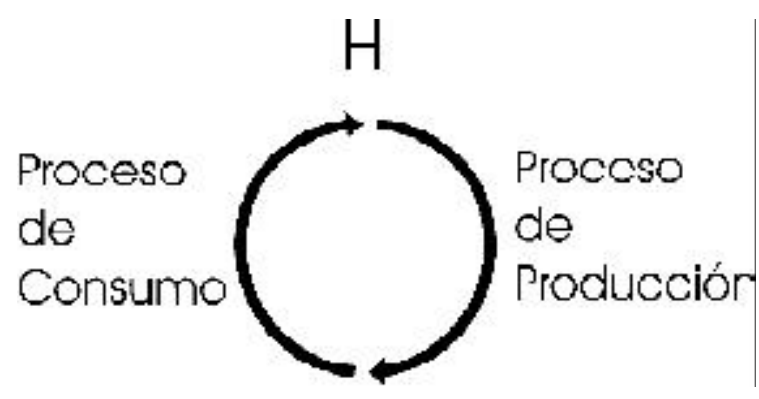

En términos físicos la energía potencial se transfirió en la forma de calor y trabajo a los bienes, y luego, esa energía gastada se recupera con la correspondiente transferencia de calor y trabajo. En términos económicos, la potencia del hombre (H) al ponerse en acto da inicio al proceso de producción, obteniendo como resultado del mismo una cantidad de bienes $\left(\mathbf{Q}_{B}\right)$, y luego, en el proceso de consumo recupera $\bigcirc$ amplía la potencia original (H) .

En los gráficos anteriores hemos estado apreciando una vista vertical que muestra el eje $\mathbf{H}$, ahora apreciemos una vista horizontal que muestre el plano $\mathbf{B}$ formado por los ejes $\mathbf{B}_{1}$ y $\mathbf{B}_{2}$ correspondiente a los bienes.
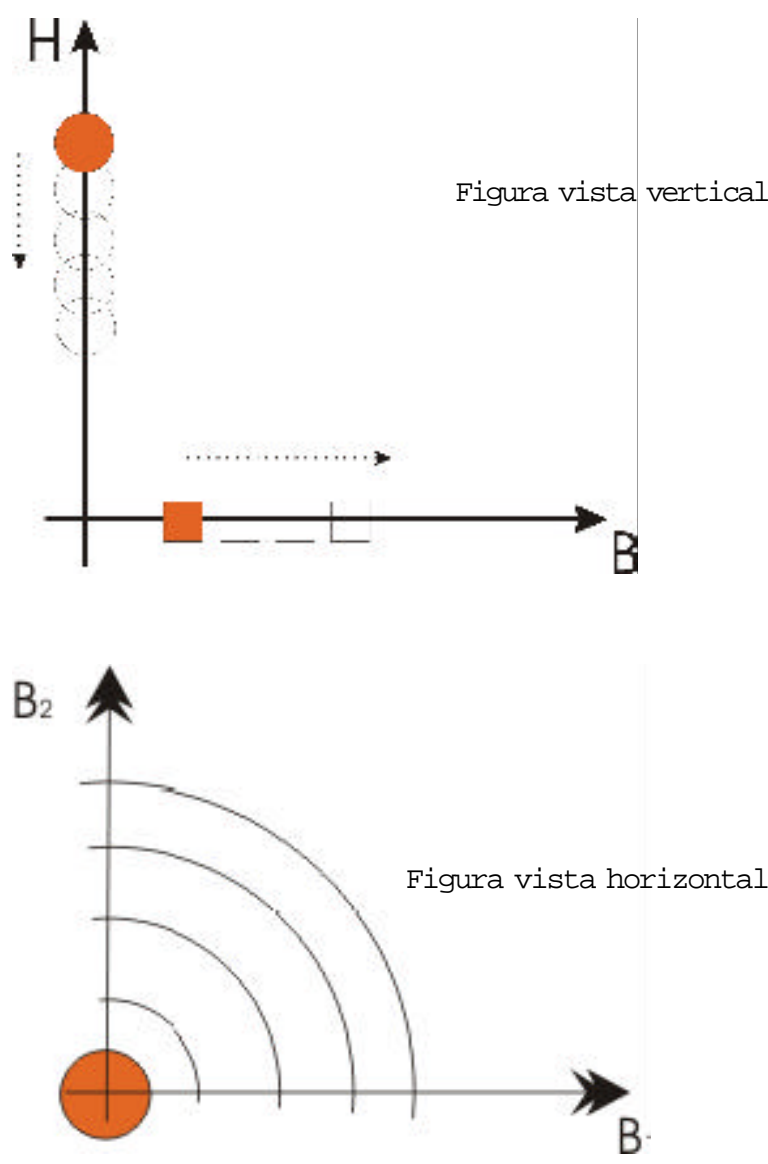

El plano $\mathbf{B}_{1}-\mathbf{B}_{2}$ grafica el universo de todos los bienes producidos por el hombre. Generalmente la teoría económica ha tenido un enfoque reducido a este espacio bidimensional del plano horizontal, estudiando las relaciones entre precios y cantidades; en cambio, la introducción de la dimensión humana nos permite un enfoque tridimensional.

El proceso de consumo de estos bienes restablece la energía potencial biológica gastada en producirlos.

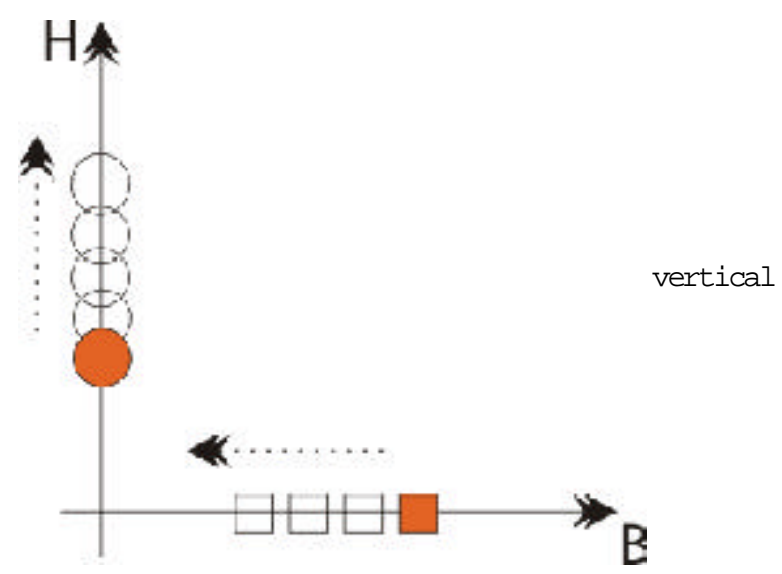

De esta manera proponemos la vinculación de los desarrollos teóricos del profesor Figueroa con esta idea de la potencia de H. El proceso de producción y el proceso de consumo se generan al interior de un mismo proceso económico. En el primero, las potencias de H son transferidas en la forma de trabajo y producen bienes. En el segundo proceso, la energía contenida en los bienes es transferida al hombre en la forma de consumo y restablece la potencia original.

Hasta ahora solo hemos entendido estos procesos en su sentido físico y biológico. Este ciclo de producción y consumo nos aproxima a la idea del telos de la economía. Quedarnos únicamente en el plano horizontal solo nos hubiera permitido apreciar el mundo de los bienes; sin embargo, cuando observamos el espacio tridimensional generado por la vertical, apreciamos tanto el origen productivo de los bienes como también la finalidad a la que están destinados.

No obstante, es necesario advertir que hasta ahora estamos haciendo un análisis parcial reducido a los aspectos físicos y biológicos, no debemos olvidar que las dimensiones de la natura- 
leza humana son mucho más complejas que esta simple visión preliminar.

\subsubsection{Descomposición analítica de la dimensión humana ( $\boldsymbol{\eta})$}

Si analizamos el proceso económico en el modelo de reproducción simple sin excedente económico observamos que:

$\mathrm{H}_{1}$ puede ser definido como la potencia del hombre al inicio del proceso económico en el momento $t_{1}$.

$\mathrm{H}_{2}$ puede ser definido como la potencia del hombre al final del proceso económico en el momento $t_{2}$.

Luego, conforme al modelo simple que reproduce la existencia del hombre, las energías consumidas al interior del proceso son repuestas al interior del mismo.

Por consiguiente:

$$
\mathrm{H}_{1}=\mathrm{H}_{2}
$$

Para que esta igualdad se mantenga a un nivel de reproducción simple, el proceso económico debe producir lo necesario para que el hombre mantenga su existencia y el ciclo se repita sucesivamente.

Porque en el caso de no ser así:

$$
\mathrm{H}_{1}>\mathrm{H}_{2}
$$

Si el proceso productivo no genera lo necesario para reproducir la existencia del hombre, entonces, estaremos frente al caso de una sociedad cuya existencia tiende a desaparecer, es lo que llamamos pobreza absoluta. Medido en términos de potencia decreciente.

$\mathrm{H}_{\mathrm{n}}$ se define como la cantidad de energía transferida al interior del proceso económico para recrear la existencia del hombre.

$\mathrm{H}_{\mathrm{n}}$ medido en términos de potencia recuperada.

Ahora bien, si el proceso económico tiene la capacidad de producir más de lo necesario para recrear la existencia humana estaremos frente al caso de una sociedad cuya existencia tiende a modificarse en un sentido de ampliación, es decir, un proceso de reproducción ampliada.

\section{$\mathrm{H}_{1}<\mathrm{H}_{2}$}

El incremento de $\mathbf{H}_{1}$ a $\mathbf{H}_{2}$ no debe ser entendido como un incremento cuantitativo, se trata de un incremento que modifica la naturaleza humana. Para expresarlo de una manera sencilla, imaginemos un proceso económico que recibe el trabajo de 10 hombres al inicio, lógicamente, al final del proceso saldrán los mismos 10 hombres con sus energías restablecidas, solo que en el caso de un proceso de reproducción ampliada suponemos que los 10 hombres habrán incrementado cualitativamente sus capacidades, habrán modificado su Ser.

$\mathrm{H}_{e}$ se define como la cantidad de energía transferida en el proceso económico que modifica qué es el hombre.

$\mathrm{H}_{\mathrm{e}}$ medido en términos de potencia ampliada, que implica cambios de calidad.

Lo funcional de la unidad de medida propuesta se manifiesta en que nos sirve tanto desde un criterio cuantitativo, correspondiente al proceso de reproducción simple, como desde un criterio cualitativo, correspondiente al proceso ampliado y que permite expresar la modificación de la naturaleza humana al adquirir nuevas capacidades.

En el proceso histórico de la humanidad, estas dos dimensiones de $\mathrm{H}$ constituyen la primera descomposición a la que llegamos en nuestro análisis. Así, el hombre entendido como proceso, como movimiento es:

$\mathrm{H}=\mathrm{H}_{\mathrm{n}}+\mathrm{H}_{\mathrm{e}}$

'Lo producido' tiene un significado complejo, es el conjunto de bienes necesarios para reproducir la existencia humana, entendidos como insumos de su proceso productivo, como también y principalmente, es el conjunto de capacidades desarrolladas por el hombre en el acto mismo de trabajar. Nosotros pondremos especial énfasis al aspecto de capacidades.

\subsubsection{La potencia y la ley de la entropía}

El proceso de transferencia de calor llega a un momento en que se detiene, ya no es posible generar trabajo:

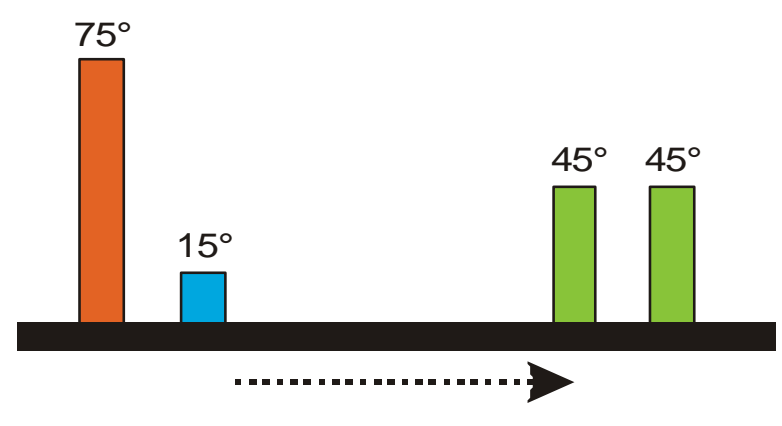

Proceso de transferencia de calor 
El proceso económico supuso, en los acápites anteriores, que el ciclo productivo se repetiría indefinidamente, no obstante, al considerar la ley de la entropía podemos comprobar que en el largo plazo este ciclo no podrá continuar.

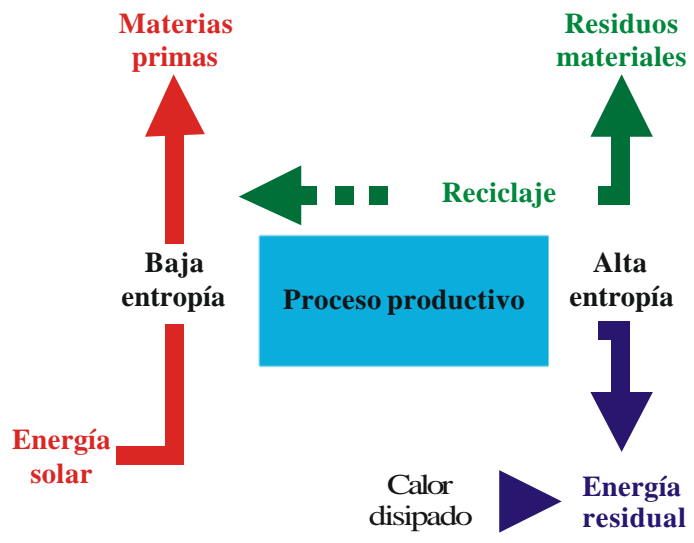

La primera comprobación es que los recursos naturales sufren una ininterrumpida, irrevocable e irreversible degradación. Podríamos, entonces, replicar que el sistema termodinámico del planeta Tierra es abierto, y que el Sol es una fuente infinita de energía permitiendo la continuación de su proceso. Pero, aún el Sol se someterá algún día a la ley de la entropía. Podríamos, luego, especular filosóficamente, diciendo que el ciclo iniciado con el Big Bang y la expansión del Universo, será seguido por un proceso de contracción y terminará en un Big Crunch. Ese momento está tan lejano que podemos asumir la infinitud del proceso.

Sin embargo, la sociedad moderna, tal como la conocemos hoy, solo es factible por el uso de energía fósil (carbón, petróleo, gas) y algunos científicos señalan que su agotamiento se encuentra relativamente cerca. Además, es necesario considerar el efecto de contaminación del medio ambiente producido por este tipo de energía. Parece que vamos en el camino de la negación de la vida, sin necesidad de referirnos a la ley de la entropía.

Por el contrario, lo interesante de los procesos vitales es que, en el corto plazo, contradicen la ley de la entropía. Un cuerpo viviente al procesar materiales simples produce estructuras complejas, esto es, produce un incremento de complejidad $\circ$ un descenso de la entropía. La Economía Ecológica nos invita a la búsqueda creativa de procesos productivos que tengan el equilibrio vital como finalidad primera. Solamente en el largo plazo, inevitablemente, se impondrá la creciente entropía del sistema general de la naturaleza.

«Vida, término que se utiliza para englobar las actividades características de todos los organismos, desde las algas unicelulares hasta las plantas y animales superiores. De todas ellas, la característica más determinante es la reproducción».

«La reproducción se basa en la formación de copias idénticas, o casi idénticas, de estructuras complejas a partir de materiales simples».

«El aumento de complejidad inherente a la formación de organismos vivos a partir de sus precursores, distingue a estos procesos biológicos de crecimiento y reproducción de otros procesos físicos como la condensación o la cristalización».

«Este incremento parcial de complejidad o descenso de entropía, parece contradecir la segunda ley de la termodinámica, la cual plantea que la entropía aumenta siempre en los procesos naturales espontáneos».

«Sin embargo, se puede demostrar que la entropía global aumenta siempre, tanto en los cambios que tienen lugar en el medio, como en los que se llevan a cabo en los propios organismos» ${ }^{12}$.

La vida implica el proceso desde lo simple hacia lo complejo. La vida humana como proceso histórico social confirma este incremento de la complejidad o descenso de la entropía, desde el hombre primitivo que en su simpleza era todavía casi un animal hasta el hombre moderno que en su complejidad nos hace avizorar formas superiores de sociedad.

En este contexto, el proceso económico tiene dos movimientos simultáneos y contradictorios:

1. Como proceso físico de fabricación, se mueve de niveles de baja entropía a niveles de alta, degradando la potencia del sistema global.

2. Como proceso vital y social, se mueve de formas simples hacia estructuras complejas, incrementando la complejidad social o descendiendo la entropía del sistema vital.

En el primer caso, los procesos físicos de fabricación pueden ser clasificados por el grado de entropía que generan. Es preciso señalar que el grado de entropía generado por la actividad productiva de la sociedad moderna actual, basándose en energía fósil, es el más grave; tiene formas de producción que generan un severo 
incremento de la entropía global del sistema. Y, complementariamente, los actuales hábitos de consumo refuerzan esa tendencia, mientras el consumo endosomático que demanda bajos niveles de calorías decrece relativamente, el consumo exosomático, con un elevado gasto de calorías, crece.

En el segundo caso, los procesos sociales nos introducen al terreno de las formas de conciencia, que todavía no hemos abordado en esta investigación. Continuemos, ahora, ese recorrido que va de lo más simple a lo más complejo, y que comenzó con los aspectos físicos y biológicos del proceso económico.

\subsection{LA POTENCIA EN SU SIGNIFICADO SOCIAL Y VITAL}

La vida tiene la capacidad de procesar materiales simples y producir estructuras complejas, en esto consiste el proceso de reproducción de la vida en general.

\subsubsection{La potencia: de lo simple a lo complejo}

El hombre, en lo personal y en lo social, tiene la capacidad de elevar su potencia, recreando su propia vida. Es capaz de reponer las energías biológicas gastadas en el proceso de producción de bienes, consumiendo lo fabricado por el mismo, y, además, es capaz de producir excedentes.

Sin embargo, la producción de excedentes por sí mismos no genera necesariamente la elevación de su potencia, por ejemplo, la cantidad de alimento que el hombre puede consumir tiene un límite biológico, consumir más no eleva su potencia.

La primera forma en que el hombre logra elevar su potencia, más allá de lo puramente biológico, es con el incremento de su saber sobre la naturaleza; el mismo acto productivo le permite elevar su conocimiento científico. La historia de la ciencia nos ilustra ampliamente sobre las implicancias de cada descubrimiento en el incremento de las potencias humanas.

Este incremento de la potencia (H) no es susceptible de ser medido con unidades propias de las ciencias físicas de manera directa, como sí podríamos hacerlo con la categoría física de energía potencial. Solamente puede ser medido físicamente cuando se manifiesta como acto, es únicamente en el fruto del trabajo que podemos medir la potencia ampliada (DH) .

Es por ello, que propusimos que la unidad de potencia fuese considerada como un número ordinal, el incremento de la potencia (DH) no es simplemente cuantitativo, sino que es principalmente cualitativo. Este incremento va más allá de la Física.

El hombre, en su complejidad, no puede ser reducido a simple cuerpo biológico, el hombre es mucho más y podemos señalar como ejemplo una dimensión adicional: la libertad. Este ejemplo nos muestra cómo el incremento de la potencia humana puede ser muy grande cuando la libertad creativa se pone en acto; vislumbramos, entonces, ese horizonte infinito de la naturaleza humana.

Es necesario, pues, que hagamos un esfuerzo de clasificación de toda esta complejidad que incrementa la potencia del hombre, con un criterio que trascienda el estrecho ámbito de lo físico.

\subsubsection{Fuentes para una clasificación de las po- tencias del hombre}

Como fuente de consulta, para la exploración de las diversas posibilidades de clasificación de las potencias del hombre, vamos a recurrir a los estudios de:

- Abraham Maslow, sobre una teoría de la motivación humana,

- Javier Iguiñiz, sobre un ensayo de clasificación de la multidimensionalidad de la pobreza,

- Sabina Alkire, sobre las dimensiones del desarrollo humano, quien a su vez nos remite a los estudios de:

- John Finnis, sobre los valores humanos básicos (Basic Reasons for Action),

- Martha Nussbaum, sobre capacidades humanas (Basic Human Capabilities),

- Robert Cummins, sobre calidad de vida,

- Manfred Max-Neef, sobre categorías axiológicas (Axiological Categories),

- Deepa Narayan et al, sobre las dimensiones del bienestar (Dimensions of Well-Being),

- Shalom Schwartz, sobre los valores humanos universales (Universal Human Values),

- Maureen Ramsay, sobre las necesidades sicológicas universales (Universal Psychological Needs), 
- Doyal \& Gough, sobre las necesidades humanas básicas (Basic Human Needs),

- Frances Stewart, sobre vida plena.

Trataremos de encontrar, en estos diferentes enfoques, el camino para definir los diferentes aspectos de la dimensión potencia. Y tomaremos la teoría de la motivación humana de A. Maslow como esquema analítico de esta búsqueda. Sin embargo, nuestro enfoque principal es el de capacidades en un sentido pleno y no solamente psicológico. Al respecto Sabina Alkire recoge de Amartya Sen una definición de bienestar que toma al hombre integralmente, y que nos servirá en este esfuerzo clasificatorio:

«By human development, I will mean human flourishing in its fullest sense - in matters public and private, economic and social and political and spiritual».

"This is wider than some definitions of well-being that relate only to material deprivations or to aspects of well-being that can be publicly provided...»

«For human development consists, as Sen would argue, of other things besides well-being achievement for any particular person at time $t$; it also considers their agency aspects - what they are able to do about the causes they follow, such as space exploration or saving the seals».

«It also consists of non-individualist aspects of social living that are of utmost importance» ${ }^{13}$.

\subsubsection{Nueva lectura de A. Maslow}

Para A. Maslow la fuerza que mueve la acción humana es la necesidad, la motivación del movimiento del hombre es la necesidad. Es un impulso que genera la actividad humana para satisfacer esa necesidad, es algo así como el reclamo de un recipiente vacío que exige ser llenado. Cuando se colma el recipiente el impulso cesa, y pasa a llenar otro recipiente, otra necesidad superior.

«...el principio primordial de organización de la vida motivacional humana es la ordenación de las necesidades básicas en una jerarquía de mayor o menor prioridad.... ${ }^{14}$

Enfocar esta motivación como necesidad nos impide ver el proceso económico integralmente y nos lleva a unilateralizar sólo un aspecto de él, es decir, sólo la fase del proceso de consumo. Pretendemos, por nuestra par- te, ver el proceso económico en sus dos aspectos: como proceso productivo y como proceso de consumo, es decir, como potencia de $\mathrm{H}$ en acto (producción) y como potencia de $\mathrm{H}$ restablecida (consumo) .

Nosotros intentamos seguir este mismo esquema analítico pero desde otra perspectiva:

- No nos interesan los recipientes vacíos solamente.

- No nos interesa el impulso por llenar el recipiente vacío con bienes, lo que nos interesa es el recipiente lleno.

- ¿Lleno de qué?

- Lleno de capacidades.

- Lleno de potencias.

Lo que nos interesa es:

- ¿Qué puede hacer el recipiente fisiológico al fluir su potencia contenida?

- ¿Qué puede hacer el recipiente de seguridad y regularidad al fluir su potencia contenida?

- ¿Qué puede hacer el recipiente relacional al fluir su potencia contenida?

- ¿Qué puede hacer el recipiente de autovaloración y reconocimiento al fluir su potencia contenida?

- ¿Qué puede hacer el recipiente cognitivo al fluir su potencia contenida?

- ¿Qué puede hacer el recipiente estético al fluir su potencia contenida?

- ¿Qué puede hacer el recipiente de realización plena al fluir su potencia contenida?

\subsubsection{Clasificación de las potencias del hombre}

Siguiendo el esquema analítico de Maslow podemos clasificar las potencias humanas de la siguiente manera:

- La potencia como capacidad fisiológica.

- La potencia como capacidad de seguridad y regularidad.

- La potencia como capacidad relacional.

- La potencia como capacidad de autovaloración y reconocimiento.

- La potencia como capacidad cognitiva.

- La potencia como capacidad estética.

- La potencia como capacidad de realización plena.

\section{- La potencia como capacidad fisiológica}

La capacidad fisiológica es el aspecto que más hemos desarrollado en los acápites anteriores, suponiendo que los demás aspectos no 
existían. La mayoría de los autores mencionados toma este aspecto como el primero de todos, en diferentes enfoques que van desde el análisis de las necesidades humanas hasta el análisis de las capacidades.

Comencemos, pues, con los estudios de Maslow, quien toma las necesidades fisiológicas como punto de partida de su teoría de la motivación:

«Si todas las necesidades están sin satisfacer, y el organismo, por tanto, está dominado por las necesidades fisiológicas, las restantes necesidades simplemente pueden ser inexistentes o ser desplazadas al fondo».

«Entonces, resulta claro caracterizar al organismo entero diciendo simplemente que tiene hambre porque la conciencia está completamente embargada por el hambre».

«Todas las capacidades se ponen al servicio de satisfacer el hambre, y la organización de dichas capacidades está casi enteramente determinada por el único propósito de satisfacer el hambre» ${ }^{15}$.

El enfoque de Maslow parte del análisis de los aspectos psicológicos de la naturaleza humana para interpretar los impulsos que mueven al hombre, como homeostasis y como apetito.

Sin embargo, tomando como punto de partida el enfoque de Maslow, podemos desarrollar lo que en nuestro lenguaje llamaríamos la urgencia por restablecer la potencia fisiológica, la urgencia por restablecer el contenido del recipiente vacío, imprescindible para la existencia del Ser, y que se traduce en la palabra hambre, remarcando que, para nosotros, el hambre tiene una connotación social y no únicamente biológica y psicológica individual.

Los demás autores recogen esta primera potencia de diferentes maneras, unos lo hacen como capacidad fisiológica otros como necesidad:

Necesidad de Subsistencia (Manfred Max-Neef) Life Capability: being able to live to the end of a normal length, not dying prematurely or before one's life is so reduced as to be not worth living. Bodily Health Capability: being able to have good health, to be adequately nourished, to have adequate shelter (Martha Nussbaum) ${ }^{16}$.

Material Well-being: having enough food, assets, work. Bodily Well-being: Being and appearing well health, physical environment (Deepa Narayan) ${ }^{17}$.
Basic reasons for action: life itself (its maintenance and transmission, health) (John Finnis) ${ }^{18}$.

Nutritional food and water, protective housing, health care, physical environment (Doyal \& Gough) ${ }^{19}$.

El telos de la actividad económica del hombre tiene en primer lugar que asegurar la existencia misma, sea que la llamemos necesidad de subsistencia, capacidad de vivir, salud corporal, bienestar material, bienestar corporal, vida misma o necesidades nutricionales. Todos los autores ponen su atención en este primer aspecto.

La diferencia con nuestro planteamiento es que la potencia fisiológica supone tanto el proceso de producción como el proceso de consumo. Enfocar esta potencia como necesidad nos impide ver el proceso integralmente y nos unilateraliza solo como proceso de consumo.

Maslow introduce, además, una condición que consideramos de suma importancia: la jerarquía de la necesidad fisiológica, que se impone sobre todas las necesidades humanas. El hambre hace que el hombre no piense en otra cosa que no sea alimento, sin embargo, una vez satisfecho puede abrirse a todas las otras dimensiones de su naturaleza.

Entendemos la potencia del hombre en el sentido de capacidad fisiológica como el conjunto de energías biológicas que posee un trabajador al inicio del proceso de producción y que en el proceso mismo serán transferidas como energía a los bienes producidos.

\section{- La potencia como capacidad segura y regular}

Una vez que hemos logrado restablecer la potencia fisiológica del hombre, surge la pregunta sobre el futuro: ¿comeremos mañana? ¿tendremos techo y cobijo al llegar la noche? ¿podremos curarnos si nos enfermamos?. La pobreza en América Latina hace que estas preguntas no tengan una fácil respuesta. Amplios sectores de nuestra población solo pueden saciar precariamente su hambre inmediata sin saber que les depara el mañana. Saber si el cíclico proceso de producción y consumo va continuar regularmente proporciona una estabilidad que eleva la potencia humana.

El enfoque de necesidades nos presenta el hambre y solo sigue con la pregunta sobre el 
próximo hambre; en cambio, el enfoque de capacidades nos plantea otro tipo de siguiente pregunta: ¿tendré trabajo mañana?, como continuación del cíclico proceso de producción y consumo. La mayor parte de nuestra población económicamente activa está asociada a la peruanísima palabra «cachuelo», desde el consultor altamente especializado que no sabe si mañana tendrá un nuevo contrato hasta el vendedor ambulante que no sabe si logrará vender ese «chicle, caramelo, cigarrillo...» en las próximas horas para poder comer.

Otra forma en que se manifiesta esta capacidad es la ausencia de miedo. Lo vivido en el Perú en las décadas de los ochenta y noventa nos trae a la memoria la importancia de la ausencia de miedo para elevar las potencias de una sociedad. Y el miedo puede ser de tal magnitud que trastoca las jerarquías de necesidad, poniéndose en primer lugar.

Continuando con A. Maslow, este autor nos habla en el segundo lugar de su jerarquía de las necesidades de seguridad:

«Si las necesidades fisiológicas están relativamente bien gratificadas, entonces surgirá una nueva serie de necesidades, que se pueden clasificar aproximadamente como necesidades de seguridad (seguridad, estabilidad, dependencia, protección, ausencia de miedo, ansiedad y caos; necesidad de una estructura, de orden, de ley y de límites; fuerte protección, etc.)» ${ }^{20}$

La regularidad del ciclo de producción y consumo eleva la potencia humana; sin embargo, es preciso señalar que la medición en términos termodinámicos de esta capacidad ya no puede hacerse fácilmente, y si lo hacemos solo alcanzaremos una medición incompleta, dejando sin ponderación lo principal de este aspecto de la potencia, porque lo principal es de naturaleza subjetiva. Por ello, reiteramos, la potencia no es una medida cardinal sino que, por el contrario, se trata de un número ordinal; solamente cuando esta potencia se pone en acto o demanda bienes para ser restablecida es que podemos cuantificarla.

La repetición regular del ciclo nos permite planear el futuro, organizando de una mejor manera el proceso económico. Por ejemplo, el conocimiento de una demanda futura nos permite asignar los recursos productivos de una mejor manera. Este conocimiento no es susceptible de medición en términos termodinámicos pero constituye, cualitativamente, una potencia superior, aunque de carácter intangible por tratarse de una forma de conciencia. El proceso mismo produce este conocimiento de las regularidades.

Los demás autores también recogen esta segunda potencia de diferentes maneras:

Necesidad de Protección (Manfred Max-Neef)

Bodily Integrity Capability: Being able to move freely from place to place, having one's bodily boundaries treated as sovereign, being able to be secure against assault, including sexual assault, child sexual abuse; having opportunities for sexual satisfaction and for choice in matters of reproduction (Martha Nussbaum) ${ }^{21}$.

Security: civil peace, a physically safe and secure environment, personal physical security, lawfulness and access to justice, security in old age, confidence in the future. (Deepa Narayan) ${ }^{22}$.

Security in childhood, physical security, economic security. Safe birth control/childbearing. (Doyal $\&$ Gough) ${ }^{23}$.

Security: safety, harmony and stability of society, of relationships and of self. (Shalom Schwartz) ${ }^{24}$.

Entendemos la potencia del hombre en el sentido de capacidad y seguridad, y regularidad como la estabilidad sicológica que posee un trabajador al inicio del proceso de producción y que en el proceso mismo será transferida como intangible en los bienes producidos.

¿Qué hace la diferencia, por ejemplo, entre un chocolate comprado en Wong y un chocolate de la misma marca comprado en Santa Isabel? La diferencia es que en el primero está contenida el alma de Erasmo Wong, es decir, ese trabajador de la caja registradora o aquel que nos llena el paquete nos trasmite una cultura organizacional que le proporciona seguridad y estabilidad. Ese chocolate de Wong tiene en su interior capacidades objetivadas de la potencia como regularidad, estabilidad y seguridad. En cambio, en el segundo, tenemos un chocolate sin alma. Nos lo entrega un trabajador «mercenario» que no sabe si tendrá empleo mañana y que no es partícipe de ninguna cultura organizacional que lo vincule y le proporcione estabilidad. Nosotros como compradores reconocemos la diferencia 
entre esos dos chocolates de la misma marca, pero esa diferencia no puede ser medida en términos físicos, es intangible.

\section{- La potencia como capacidad estructural y relacional}

Prosiguiendo con A. Maslow, él nos habla en el tercer lugar de su jerarquía de las necesidades sicológicas de amor, afecto y pertenencia.

«Si tanto las necesidades fisiológicas como las de seguridad están bien satisfechas, surgirán las necesidades de amor, afecto y sentido de pertenencia».

«Las necesidades de amor suponen dar y recibir afecto».

"Cuando están insatisfechas, una persona sentirá intensamente la ausencia de amigos, de compañero o de hijos. Tal persona tendrá hambre de relaciones con personas en general -de un lugar en el grupo o la familia- y se esforzará con denuedo por conseguir esta meta..... ${ }^{25}$.

Nos parece discutible el criterio de jerarquización que aplica Maslow. Aceptamos la indiscutible primacía de las necesidades fisiológicas, sin embargo, no compartimos el criterio de que las necesidades afectivas se subordinen a otras necesidades. No creemos que las demás necesidades sigan una regla de jerarquización en general, creemos que cada caso particular y cada cultura pueden desarrollar diferentes prioridades según las circunstancias que las envuelvan.

La perspectiva sicológica individual también nos limita en el desarrollo clasificatorio desde nuestro enfoque de capacidades. Es así como, ampliando el enfoque de Maslow, una perspectiva social de la unidad de potencia nos permite abordar este aspecto de una manera diferente.

La necesidad de pertenencia tiene su complemento en el grupo al que se desea pertenecer, el hombre es un ser eminentemente social. Ese impulso psicológico de carácter afectivo propio del Yo, precisamente, se realiza en el encuentro con el Otro. La consecuencia de los impulsos de amor, afectividad y pertenencia es la construcción de un tejido de relaciones de carácter diverso que generan muchas formas de estructura relacional.
Las estructuras relacionales, el tejido de vínculos humanos, la pertenencia a redes organizacionales, es lo que nos permite hablar de potencias del hombre. El desarrollo organizacional y su consolidación en formas institucionales es lo que permite el incremento de las potencias del hombre. La cooperación en el proceso productivo -léase división del trabajo- ha permitido que la humanidad amplíe su potencia a niveles muy elevados.

Los demás autores también recogen este aspecto de diferentes maneras:

Necesidad de afecto, comprensión, participación. (Manfred Max-Neef)

Affiliation Capability: being able to live for and toward others; to recognize and show concern for other human beings; to encage in various forms of social interaction; to be able to imagine the situation of another and have compassion for that situation; to have the capability for both justice and friendship; protecting this capability means protecting institution that constitute and nourish such forms of affiliation, and also protecting the freedoms of assembly and political speech.

Having the social bases of self-respect and nonhumiliation; being able to be treated as a dignified being whose worth is equal to that of others; this entails, at a minimum, protections against discrimination on the basis of race, sex, religion, caste, ethnicity, or national origin. (Martha Nussbaum) $^{26}$.

Social Well-being: being able to care for, bring up, marry and settle children self respect and dignity, peace, harmony good relations in the family/community. (Deepa Narayan) ${ }^{27}$.

Significant primary relationships (Doyal \& Gough).

Basic reasons for action: friendship various forms of harmony between and among individuals and groups of persons, living at peace with others, neighborliness, friendship. (John Finnis) ${ }^{28}$.

Nos parece de especial interés la propuesta de Martha Nussbaum, que nos vincula directamente con la propuesta central en esta investigación: el telos de la economía. El hombre es el motivo central, la recreación de la vida es lo que debería mover la actividad económica. Entonces, cuando Nussbaum nos presenta la 
capacidad de vivir para y hacia otros, de reconocer y mostrar preocupación por otros seres humanos, la capacidad para interactuar socialmente, la capacidad de imaginarse la situación de otro y tener compasión para esa situación, teniendo las bases sociales para el respeto de uno mismo y el tratamiento con dignidad; cuando ella nos presenta todas estas capacidades y luego observamos nuestra realidad, tenemos la impresión de que la propuesta fuese una ilusión utópica.

Sin embargo, cuando nos detenemos y analizamos con cuidado el significado de estas capacidades humanas, podemos afirmar desde la más rigurosa racionalidad, que las capacidades de afiliación propuestas por Nussbaum necesariamente elevarían las potencias del hombre. De la misma manera, esa rigurosidad nos permite señalar la irracionalidad de la realidad actual, una realidad que niega y excluye al hombre.

Las relaciones económicas pueden ser potencias o barreras para el desarrollo de la sociedad. Al respecto Karl Marx desarrolló toda una concepción que explica este proceso. No vamos a ser redundantes repitiéndola, simplemente señalamos lo fundamental de esa explicación:

«Al llegar a una determinada fase de desarrollo, las fuerzas productivas materiales de la sociedad entran en contradicción con las relaciones sociales de producción existentes, o, lo que no es más que la expresión jurídica de esto, las relaciones de propiedad dentro de las cuales se han desenvuelto hasta allí».

«De formas de desarrollo de las fuerzas productivas, estas relaciones se convierten en trabas suyas».

«Y se abre una época de revolución social.... ${ }^{29}$.

Aunque compartimos aspectos centrales de esta teoría, tomamos distancia y precisamos que nuestra preocupación se centra en la pobreza absoluta de América Latina, el Sur de África y el Asia del Sur, con la implicancia de exclusión y/o destrucción de una parte de la humanidad, mientras que la teoría de la explotación de Marx se centra en la pobreza relativa de países como la Inglaterra de su época, generada por la apropiación privada de los excedentes económicos en la forma de plusvalor.

En lo referente a esta potencia económica como capacidad estructural y relacional, podemos observar cómo desde la organización más pequeña, una simple unidad productiva (por ejemplo: una empresa), hasta la organización social en su conjunto, es evidente que su potencia económica se elevará como consecuencia del desarrollo de la red de relaciones constitutivas de su estructura.

La historia de las ciencias administrativas nos presenta muchos ejemplos del impacto de una mejor organización empresarial en los resultados del proceso económico. Por ejemplo, tomemos la comparación entre dos empresas, una con largo tiempo de operación y otra recién constituida. La primera tendrá procedimientos, sistemas, normas, políticas, estrategias y objetivos perfectamente estructurados. Todos los trabajadores «pertenecientes» a esta organización conocerán la red de relaciones, mientras que la segunda estará envuelta en la confusión y el caos inicial, como resultado de la ausencia de vínculos y sentido de «pertenencia» de trabajadores recién contratados y desconocidos entre sí, por más que en el proyecto de inversión del fundador estén incluidos los manuales de función y el diseño teórico de la estructura organizacional. La consolidación de esta estructura, en la práctica, constituye una potencia valiosísima de las unidades empresariales. Lo mismo podríamos decir de un simple chofer de Tico que ha construido una cartera de clientes vía teléfono celular, en comparación con un taxista «pirata» que solamente gasta gasolina dando vueltas sin pasajeros. La importancia del tejido de relaciones humanas tiene una gran relevancia para la potencia de una unidad económica como, también, para una sociedad.

Los procesos económicos y los procesos sociales en general, desarrollan sus propias potencias organizativas en el acto mismo de su proceso, ciclo a ciclo van perfeccionando las estructuras relacionales elevando, así, su potencia. Nuevamente señalamos la intangibilidad de esta potencia que es una forma de conciencia y que no puede ser medida en términos termodinámicos. Por ello, reiteramos, la potencia no es una medida cardinal sino que, por el contrario, se trata de un número ordinal; solo cuando esta potencia se pone en acto podemos cuantificarla.

\section{- La potencia como capacidad de autovalora- ción y reconocimiento}

Continuando con la teoría de la motivación de Maslow, que nos está sirviendo como 
esquema analítico para desarrollar nuestro propio enfoque, este autor nos presenta, ahora, su cuarta necesidad:

«La satisfacción de la necesidad de autoestima conduce a sentimientos de autoconfianza, valía, fuerza, capacidad y suficiencia, de ser útil y necesario en el mundo» ${ }^{30}$.

Surge, entonces, la pregunta: ¿en qué medida los excluidos de una sociedad ven mermada su propia potencia?

El reconocimiento por el otro es lo que nos constituye como personas; la exclusión nos empuja a la negación de nuestra propia humanidad, los excluidos ya no seríamos personas. Saberse útil y valioso para los demás, justamente, eleva nuestra propia potencia.

Los demás autores también recogen este aspecto de diferentes maneras:

Psychological Well-being: peace of mind, happiness, harmony. Including a spiritual life and religion observance. (Deepa Narayan) ${ }^{31}$

Emotions Capability: being able to have attachments to things and persons outside ourselves, to love those who love and care for us, to grieve at their absence; in general, to love, to grieve, to experience longing, gratitude, and justified anger. Not having one's emotional development blighted by overwhelming fear and anxiety, or by traumatic events of abuse or neglect. Supporting this capability means supporting forms of human association that can be shown to be crucial in their development. (Martha Nussbaum) $^{32}$

Achievement as universal human value: personal success through demonstrating competence according to social standards. (Shalom Schwartz)
El reconocimiento, desde la perspectiva de las ciencias administrativas, se manifiesta en el mercado; conquistar la lealtad de los consumidores respecto a algún producto o marca constituye un intangible valiosísimo. Por ejemplo, una empresa bien posicionada en el mercado tiene potencias que carece la nueva empresa que incursiona en él.

La recurrencia del ciclo de producción y consumo permite desarrollar esta potencia de reconocimiento y valoración. Sin embargo, de manera similar a los casos anteriores, se trata de una potencia de carácter intersubjetivo, es decir, se trata de una forma de conciencia; por consiguiente, tampoco es susceptible de ser medida en términos termodinámicos. La mayor potencia que se logra por este reconocimiento es de carácter ordinal.

\section{- La potencia como capacidad cognitiva}

Maslow excluye de las necesidades básicas los deseos de saber y de entender, y nos dice 10 siguiente:

«La razón principal de que sepamos muy poco sobre los impulsos cognitivos, su dinámica o su patología, se debe a que no son importantes clínicamente $y$, por supuesto, no lo son en la medicina clínica dominada por la tradición médico terapéutica de eliminar la enfermedads ${ }^{33}$.

El enfoque individual psicológico nos impide sopesar la verdadera potencia de la capacidad cognitiva; inclusive, nos atreveríamos a ubicar jerárquicamente esta capacidad al nivel de urgencia de las capacidades fisiológicas.

En los procesos económicos, el conocimiento científico es crucial para determinar su potencia, veamos que nos dice Manfred Max-Neef:

Table III. Max-Neef: Four Expressions of the Human Need for Understanding.

\begin{tabular}{|c|l|l|l|l|}
\hline Need & \multicolumn{1}{|c|}{ Being } & \multicolumn{1}{c|}{ Having } & \multicolumn{1}{c|}{ Doing } & \multicolumn{1}{c|}{ Interacting } \\
\hline Understanding & Critical conscience & Literature & Investigate & Settings of formative \\
& Receptiveness & Teachers & Study & Interaction \\
& Curiosity & Method & Experiment & Schools \\
& Astonishment & Educational policies & Educate & Universities \\
& Discipline & Communication & Analyze & Academies \\
& Intuition & Policies & Meditate & Groups \\
& Rationality & & & Communities \\
& & & & Family \\
\hline
\end{tabular}


Max-Neef nos presenta una interesante forma de descomponer analíticamente cada necesidad. Veamos el ejemplo del cuadro: necesidad de entender.

- Aspecto esencial: conciencia crítica, receptividad, curiosidad, disciplina, racionalidad.

- Aspecto instrumental: libros, maestros, método, medios.

- Aspecto actual: investigación, análisis, estudio, experimentación, meditación, reflexión.

- Aspecto relacional: interacción social, ínter subjetividad en diferentes ámbitos.

Las capacidades que permiten el desarrollo del conocimiento en general y el conocimiento científico en particular, según nuestra opinión, constituyen la forma de conciencia más importante para la ampliación de la potencia del hombre en el proceso económico.

Si tratásemos de jerarquizar las capacidades como lo hace Maslow con las necesidades, diríamos que las capacidades fisiológicas y las capacidades cognitivas ocupan el primer lugar de todas. Pero no en un sentido excluyente, porque solamente el desarrollo integral del hombre nos puede permitir llegar a los niveles más altos de potencia.

La producción y el consumo de conocimiento científico es parte integral del proceso económico, pero no se reduce a un simple sentido de ciencia aplicada. El conocimiento de la naturaleza nos lleva mucho más allá, nos lleva a los terrenos del saber universal. Esta capacidad cognitiva ha adquirido el sentido de saber científico recién en la actual sociedad moderna occidental, sin embargo, en su forma más general está presente en todas las formaciones sociales de la historia y siempre ha significado una elevación de la potencia del hombre.

\section{- La potencia como capacidad estética}

Maslow también excluye de las necesidades básicas los deseos de belleza, y nos dice desde su óptica sicológica lo siguiente:

«Sabemos aún menos de éstas [necesidades estéticas] que de las otras y, sin embargo, el testimonio de la historia, de las humanidades y de la estética no nos permite pasar por alto este terreno».

«Los intentos de estudiar esta área sobre una base clínica con individuos seleccionados han demostrado que, al menos, en algunos individuos hay una necesidad estética verdaderamente básica».

«Se ponen enfermos con la fealdad y se curan con los entornos hermosos; anhelan activamente, $y$ sus anhelos sólo se pueden satisfacer con la belleza. Hambre» ${ }^{34}$.

Los demás autores también recogen este aspecto de diferentes maneras:

Basic reasons for action: knowledge and aesthetic experience human persons can know reality and appreciate beauty and whatever intensely engages their capacities to know and to feel. (John Finnis) ${ }^{35}$

Senses, Imagination, Thought Capabilities: being able to use the senses, to imagine, think, and reason, and to do these things in a «truly human» way, a way informed and cultivated by an adequate education, including, but by no means limited to, literacy and basic mathematical and scientific training. Being able to use imagination and thought in connection with experiencing and producing self-expressive works and events of one's own choice, religious, literary, musical, and so forth. Being able to use one's mind in ways protected by guarantees of freedom of expression with respect to both political and artistic speech, and freedom of religious exercise. Being able to search for the ultimate meaning of life in one's own way. Being able to have pleasurable experiences, and to avoid non-necessary pain. (Martha Nussbaum) ${ }^{36}$

Lo estético es inseparable de lo vital para Friedrich Nietzsche, quien en su libro «El Nacimiento de la Tragedia» nos presenta lo que significó para la cultura helénica el encuentro entre la mentalidad apolínea y la dionisiaca. Queremos recoger una cita de este autor para expresar el significado de las capacidades estéticas como fuerza expresiva de la vitalidad del hombre; lo estético es la manifestación de lo vital, es la vida misma:

«Los dioses griegos con la perfección con que se nos aparecen ya en Homero, no pueden ser concebidos, ciertamente como frutos de la indigencia y de la necesidad... En éstas [imágenes] habla una religión de la vida, no del deber, o de la ascética, o de la espiritualidad. Todas estas figuras respiran el triunfo de la existencia, un exuberante sentimiento de vida acompaña su culto... En los 
griegos la voluntad quiso contemplarse a sí misma transfigurada en obra de arte para glorificarse ella a sí misma...»

«Esta es la esfera de la belleza, en la que los griegos ven sus imágenes reflejadas como en un espejo, los Olímpicos. Con esta arma luchó la voluntad helénica contra el talento para el sufrimiento y para la sabiduría del sufrimiento, que es un talento correlativo del artístico. De esta lucha, y como memorial de su victoria, nació la tragedia... Dado que ese mundo de dioses no puede ser encubierto del todo, como un secreto vituperable, la mirada tiene que ser desviada del mismo por el resplandeciente producto onírico situado junto a él, el mundo olímpico: por ello el ardor de sus colores, la índole sensible de sus figuras se intensifican tanto más cuanto más enérgicamente se hacen valer a sí mismas la verdad o el símbolo de las mismas. Pero la lucha entre verdad $y$ belleza nunca fue mayor que cuando aconteció la invasión del culto dionisiaco: en él la naturaleza se desvelaba y hablaba de su secreto con una claridad espantosa, con un tono frente al cual la seductora apariencia casi perdía su poder».

«En Asia tuvo su origen aquel manantial pero fue en Grecia donde tuvo que convertirse en río, porque aquí encontró por vez primera lo que Asia no le había ofrecido, la sensibilidad más excitable y la capacidad más fina para el sufrimiento, emparejadas con la sensatez y la perspicacia más ligeras. ¿Cómo salvó Apolo a Grecia? El nuevo advenedizo [Dioniso] fue ganado para el mundo de la bella apariencia, para el mundo olímpico...»

«Una gran revolución se inició en todas las formas de vida: en todas partes se infiltró Dioniso, también en el artes ${ }^{37}$.

Pedimos disculpas por lo extenso de esta cita que no se relaciona directamente con nuestro tema, sin embargo, la belleza y vitalidad de su texto lo justifican. Queremos expresar con ella la fuerza de lo estético cuando lo entendemos como algo vital, cuando nosotros mismos somos los actores de la vida, y en ella expresamos la belleza misma como proceso vital y no como contemplación estática de lo bello.

En ese sentido el proceso de recreación del hombre es un proceso de recreación estética que expresa de manera sublime qué es el hombre. La potencia del hombre en su forma de capacidad estética, nos permite entender hasta dónde llega el significado de esta dimensión en el proceso de su recreación.

\section{- La potencia como capacidad de realización plena}

Finalmente llegamos a un punto en que la concepción aristotélica de entelequia se encuentra con la concepción de autorrealización de Maslow, la causa final de todas las capacidades se resuelve en la realización plena del hombre. Veamos qué nos dice Maslow:

«Aún cuando todas las necesidades estén satisfechas, podemos esperar que, a menudo (si no siempre), se desarrolle un nuevo descontento $y$ una nueva inquietud, a menos que el individuo esté haciendo aquello para lo que él individualmente está capacitado. Lo que los humanos pueden ser, es lo que deben ser. Deben ser auténticos con su propia naturaleza» ${ }^{38}$.

Es necesario subrayar el significado de las últimas palabras: «[Los humanos] deben ser auténticos con su propia naturaleza». Esta frase de Maslow recoge un aspecto fundamental del pensamiento de Aristóteles, que más adelante desarrollaremos.

A continuación citamos algunos párrafos de la teoría de la motivación que nos permitirán entender mejor el significado de la autorrealización en Abraham Maslow:

"Las personas autorrealizadas se pueden describir como relativamente espontáneas en la conducta y mucho más espontáneas en su vida interior, pensamientos e impulsos. Su conducta está marcada por la sencillez y la naturalidad...» ${ }^{39}$

El equilibrio entre la vida interior del hombre y sus actos, se traduce en un comportamiento espontáneo, sencillo y natural. De la misma manera, la armonía entre las potencias de una sociedad y sus actos, lleva las capacidades humanas a su máximo nivel y le imprime un desarrollo continuo.

"Las personas autorrealizadas tienen un profundo sentido de identificación, simpatía y cariño por los seres humanos en general... poseen un deseo auténtico de ayudar a la raza humana... De todos mis pacientes sin excepción se podía decir que eran democráticos en un sentido muy profundo. Digo esto sobre la base de un análisis previo (Maslow, 1943) de la estructura del carácter autoritario y del democrático...» ${ }^{40}$

La realización plena de una sociedad debería traducirse en relaciones humanas solidarias, 
con un auténtico deseo de alcanzar el bienestar general. Las relaciones democráticas tienen un significado que trasciende las sociedades y las épocas históricas en que se gestaron, implican el reconocimiento universal de la dignidad del hombre. Dignidad, que como decía el renacentista Nicolás de Cusa, es la libertad del hombre.

Amartya Sen entiende la libertad como una forma superior de capacidad: la libertad de elegir la forma de vida que cada hombre y cada sociedad tengan motivos para valorar.

"In this paper I have outlined and defended an interpretation of positive freedoms. The interpretation sees freedoms in the form of particular capabilities.... ${ }^{41}$

No sólo la libertad es una capacidad superior. Cuando ésta se une a la creatividad, las capacidades humanas adquieren un despliegue que le permite alcanzar el infinito:

«Esta [la creatividad] es una característica universal de todas las personas estudiadas y observadas. No hay excepción. Cada uno, de una manera u otra, muestra una clase especial de creatividad, de originalidad o de inventiva que tiene ciertas características peculiares. Es como si esta clase especial de creatividad, al ser una expresión de la personalidad sana, se proyectase sobre el mundo o afectase a cualquier actividad que desarrolla la persona.... ${ }^{42}$.

Y a continuación tenemos una cita de Maslow que pone en discusión un aspecto crucial de esta investigación: la relación entre medios y fines:

"La mayoría de las veces las personas autorrealizadas se comportan como si para ellos los medios y los fines fueran claramente diferenciables. En general, se orientan más a los fines que a los medios, y los medios están definitivamente supeditados a esos fines» ${ }^{43}$.

El Centro de Estudios Regionales Andinos Bartolomé de las Casas del Cusco publica una selección de varios autores sobre el tema Racionalidad, Historia y Convivencia Social; entre varios ensayos hemos seleccionado Racionalidad Occidental y Racionalidad Andina: una comparación, de Antonio Peña Cabrera.

"La racionalidad occidental es idealmente la de la ciencia y la tecnología... se reduce a la coherencia lógica de medios a fines... El pensamiento pragmático moderno-decía a comienzos de siglo [José Ortega y Gasset, en El Espectador]-queda reducido a la operación de buscar buenos medios para los fines, sin preocuparse de éstos...».

"Iring Fetscher en un breve comentario a Nietzsche, ha afirmado que la ilusión del progreso no ha permitido ver a cabalidad la predominancia de los medios y la ceguera de los fines de la racionalidad occidental: el sistema de la absolutización de los medios y la ignorancia de los fines es el nihilismo completo...» ${ }^{44}$.

La economía neoclásica, impregnada consustancialmente de esta racionalidad instrumental, desarrolla una sofisticada construcción teórica en torno a los medios, y se olvida de lo central: el hombre como finalidad.

«En el mundo moderno, en el mundo gobernado por la razón instrumental todo es medio, nada es fin en sí mismo...»

«Heidegger [en su obra Ser, Verdad y Fundamento] ha explicado que la relación sujeto - objeto (que es fundamental en el nacimiento del pensamiento moderno) se da cuando se establece un vínculo de dominación con las cosas».

«Galileo por su parte dice que la ciencia se ocupa de lo medible y hace medible lo que en sí no es medible. El espacio puro, la extensión cartesiana, es el trasfondo para la acción del hombre como sujeto puro. En este proceso el hombre se enajena de la naturaleza... ${ }^{45}$.

Nosotros, inmersos en una época moderna, estamos obligados, para poder mantener el diálogo, a buscar lo medible de la potencia económica. Aunque somos conscientes que esta medición solo se recogerá por manifestaciones indirectas y aspectos parciales de la riqueza y complejidad que implica el concepto de potencia económica.

«El pensamiento occidental es causalista, al paso que el andino es seminal, esto es, sigue el curso de la vida... En la concepción moderna de la naturaleza basta la causa eficiente para explicarse los fenómenos naturales» ${ }^{46}$.

El pensamiento occidental al enfrascarse en la búsqueda de la explicación causal eficiente, definitivamente se olvida de la causa final.

Este planteamiento de Maslow sobre el hombre autorrealizado nos ha permitido continuar el desarrollo de un aspecto crucial de esta investigación: el telos de la economía. 
Otra forma de abordar esta discusión en torno a finalidades y autorrealización, la podemos apreciar en la coincidencia de Maslow con lo señalado por Aristóteles, cuando el primero dice: «Lo que los humanos pueden ser, es lo que deben ser. Deben ser auténticos con su propia naturaleza». Veamos ahora que nos dice el Estagirita al respecto:

... la felicidad es algo final y autosuficiente, que se basta a sí misma, siendo el fin de los actos realizados y por realizar.

¿Cuál puede ser la función [del hombre] ? No la mera vida, ya que de ella participan incluso las plantas, $y$ lo que estamos buscando es lo peculiar del hombre.

Por eso vamos a excluir la vida que solo es nutrición y crecimiento. Luego tenemos la vida de la percepción o sensación, pero también ésta es común al caballo, al buey y a todos los animales.

Queda, pues, una clase de vida activa de naturaleza racional. De esta naturaleza hay dos partes: una que obedece a la razón, la otra que la posee y la ejerce. Y como la vida del elemento racional tiene dos sentidos también, debemos asentar que nos referimos a la vida en el sentido de actividad..

Ahora bien, si la función del hombre es una actividad del alma que está de acuerdo con la razón... suponemos como función del hombre cierto género de vida, es decir, actividades o hechos del alma que encierran un principio racional, y que esta función en un hombre de bien consiste en ejercitar bien y noblemente dichas actividades y actos, y si en efecto toda acción se ejerce de conformidad con la excelencia que le es inherente, si así sucede, resulta que el bien humano es la actividad del alma que está en conformidad con la virtud... en una vida perfecta ${ }^{47}$.

Los demás autores también recogen este aspecto de diferentes maneras:

Basic reasons for action: Self-Expression, or Practical Reasonableness the corresponding good is harmony among one's judgments, choices, and performances - peace of conscience and consistency between one's self and its expression. Basic reasons for action: Religion most persons experience tension with the wider reaches of reality. Attempts to gain or improve harmony with some more-thanhuman sources of meaning and value take many forms, depending on people's worldviews. Thus, another category is Peace with God, or the gods, or some monotheistic but more-than-human source of meaning and value. (John Finnis)

Senses, Imagination, Thought Capabilities: Being able to use the senses, to imagine, think, and reason - and to do these things in a "truly human» way, a way informed and cultivated by an adequate education, including, but by no means limited to, literacy and basic mathematical and scientific training. Being able to use imagination and thought in connection with experiencing and producing self-expressive works and events of one's own choice, religious, literary, musical, and so forth. Being able to use one's mind in ways protected by guarantees of freedom of expression with respect to both political and artistic speech, and freedom of religious exercise. Being able to search for the ultimate meaning of life in one's own way. Being able to have pleasurable experiences, and to avoid non-necessary pain. (Martha Nussbaum)

Todos ellos -desde diferentes enfoquesnos hablan de un hombre en plenitud, sin embargo, Manfred Max-Neef nos proporciona una aproximación que nos permite generalizar a todas las diversas formas de potencia.

Recapitulemos, pues, de manera general, las diferentes capacidades desde la óptica de Max-Neef :

- Aspecto esencial: naturaleza del ser humano y niveles de potencia.

- Aspecto instrumental: medios, herramientas del proceso.

- Aspecto actual: proceso productivo y proceso de consumo.

- Aspecto relacional: interacción social, ínter subjetividad en diferentes ámbitos.

- Aspecto expresivo: manifestación estética de la subjetividad.

\section{Universal Human Values}

Power

Social status and prestige, control or dominance over people and resources.

Achievement Personal success through demonstrating competence according to social standards.

Hedonism Pleasure and sensuous gratification for oneself.

Stimulation Excitement, novelty, and challenge in life. 
Self-direction

Independent thought and action-choosing, creating, exploring.

Universalism

Understanding, appreciation, tolerance, and protection for the welfare of all people and for nature.

Benevolence

Preservation and enhancement of the welfare of people with whom one is in frequent personal contact.

Tradition

Respect, commitment and acceptance of the customs and ideas that traditional culture or religion provide.

Conformity

Restraint of actions, inclinations, and impulses likely to upset or harm others and violate social expectations or norms.

(Shalom Schwartz)

\section{COMENTARIO FINAL: MOVIMIENTO DE LA UNIDAD SIMPLE A LA MULTIPLICIDAD COM- PLEJA Y SUPERACIÓN EN LA UNIDAD DE LA P LENITUD}

Comenzamos este análisis dimensional buscando aquello que los hombres, en su actividad económica, tienen en común. Y lo hallamos en (H) la unidad de potencia económica del hombre, en la capacidad humana. Asumimos esta unidad simple después de haber descartado otras dimensiones del hombre y que son el sustento de otras teorías.

Luego, vimos como esta unidad simple de la potencia económica del hombre podía ser vista en tres sentidos diferentes: el de la Física, el Aristotélico y el de Amartya Sen. Es, entonces, cuando se nos abre toda la complejidad y multiplicidad de esta unidad simple.

Y nos adentramos en esa multiplicidad abordando una primera gran clasificación:

- La potencia en su significado termodinámico y

- La potencia en su significado social y vital.

Para luego continuar, asumiendo la propuesta de A. Maslow como esquema analítico, descomponiendo la unidad (H) en las múltiples formas de potencia como:
- Capacidad fisiológica.

- Capacidad de seguridad y regularidad.

- Capacidad estructural y relacional.

- Capacidad de autovaloración y reconocimiento.

- Capacidad cognitiva.

- Capacidad estética.

- Capacidad de realización plena.

Es, precisamente, esta final forma de potencia, como capacidad de realización plena, la que nos permite recomponer la unidad al encontrar en ella la finalidad última de toda la actividad económica. El movimiento dialéctico que se inició con la unidad simple de la potencia de (H), hizo su recorrido por toda la compleja multiplicidad de los significados de (H) y, finalmente, encuentra la superación en la negación de su multiplicidady, al mismo tiempo, logra mantener la riqueza de su complejidad en el Uno Pleno, en la realización plena (entelequia, enteléchia, $\varepsilon v \tau \varepsilon \lambda \varepsilon \chi(\alpha)$.

\subsection{COMENTARIO ADICIONAL}

En el quehacer cotidiano de nuestro trabajo y en especial de aquellos que despliegan sus capacidades profesionales en la lucha por la superación de la pobreza, la medición del desarrollo de capacidades es de suma importancia.

Como ejemplo citamos algunos fragmentos de la propuesta desarrollada para la asignación de los recursos en ayuda alimentaria a los sectores en extrema pobreza. Así, basado en los enfoques de la superación de la pobreza y desarrollo humano, preferimos aislar el efecto del ingreso monetario, para evitar sesgos. La distribución presupuestal ligada a seguridad alimentaria, se debería basar en un algoritmo de asignación y no en la discrecionalidad política («clientelismo») del gobernante de turno.

Entonces, si definimos pobreza en función del grado de acumulación del capital humano y el capital físico de una comunidad determinada para reproducir su existencia, entonces, el índice de asignación también debería estar en función de estas dos variables. 
$I$ = Indice de Asignación de la Inversión Social

$\eta=$ Variable de Acumulación de Capital Humano

$\kappa=$ Variable de Acumulación de Capital Físico

$$
I_{i}=\frac{\left\lfloor\left(\text { pop }_{i}\right)^{\gamma}\left((1-\alpha) \eta_{i}+\alpha \kappa_{i}\right)^{\rho}\right\rfloor}{\sum_{i \notin \Lambda}\left\lfloor\left(p o p_{i}\right)^{\gamma}\left((1-\alpha) \eta_{i}+\alpha \kappa_{i}\right)^{\rho}\right]}
$$

Donde:

pop $_{i}$ : es la población total del distrito i

$\eta$ : es el indicador de capital humano [desnutrición -99-]

$\kappa$ : es el indicador de capital físico [promedio de indicadores de acceso a servicios de agua, desagüe, electricidad y de desarrollo vial intermodal -93-].

Parámetros de política

$\rho$ Rho: $\quad$ parámetro de progresividad.

$\gamma$ Gamma: atenuante de población (= 1 en este caso) .

$\alpha$ Alpha: ponderación del indicador de capital físico.

$(1-\alpha)$ : $\quad$ ponderación del indicador de capital humano.

La redistribución del presupuesto de inversión social de conformidad con el índice de asignación, permitiría atender aquellos distritos que hoy se encuentran desatendidos y que de acuerdo a los criterios establecidos deberían recibir una atención prioritaria. A través de esta distribución, se gana en niveles de focalización territorial, elemento central de la política social, aportando de este modo a una mayor eficiencia, eficacia y equidad.

En el ejemplo presentado podemos apreciar como los aportes teórico-económicos y éticos de Amartya Sen pueden llevarnos a la lucha por la superación de la pobreza siguiendo caminos diferentes a los propugnados por el FMI y el Banco Mundial, sesgados por criterios vinculados a los ingresos y la renta.

\section{NOT A S}

1 Consideraremos tres tipos de sociedades capitalistas... [abstractas]: épsilon, omega y sigma. (Figueroa, 2001). La sociedad Épsilon:

- Trabajadores homogéneos.

- El capital está concentrado en la clase capitalista.

Los capitalistas buscan maximizar ganancias.
- Se produce un solo bien.

- El sistema requiere desempleo para funcionar.

- El mercado laboral es un mercado no walrasiano.

- El dueño del capital se apropia del excedente.

- El sistema está en equilibrio, se reproduce período tras período con desempleo y desigualdad.

- Los trabajadores son excluidos de tres mercados: del mercado de trabajo (los desempleados), del mercado de crédito y del mercado de seguros.

La sociedad Omega:

- Igual a la sociedadÉpsilon, salvo por una diferencia: superpoblación en relación con el stock de capital.

- El único bien se puede producir también solo con trabajo y sin capital, pero su productividad será muy baja.

- El sector de subsistencia obtiene un sustento mínimo para sobrevivir autoempleándose.

- El salario es superior al ingreso de autoempleo.

- El sistema está en equilibrio, se reproduce período tras período con desempleo y desigualdad.

La sociedad Sigma:

- Igual a la sociedad Omega, salvo por una diferencia: los trabajadores no son socialmente homogéneos.

- En la población aborigen (Z) [ex colonia] las dotaciones de capital físico y capital humano (activos políticos y culturales) serán inferiores a las del resto de la población (X) .

- El sistema está en equilibrio, se reproduce período tras período con desempleo y desigualdad.

2 Fragmentos tomados del curso de Deontología: Ética y Economía de la Universidad Católica del Perú del profesor Javier Iguiñiz.

3 Figueroa, 2001: 22.

4 Sen, 1984: 323.

Sen, 2000: 96-98.

Sen, 2000: 106 .

Aristóteles. Met. $1019 \mathrm{~b} 15$.

Aristóteles. Met. $1047 a 10$.

9 Aristóteles, Met. 1048b 25-30.

10 Aristóteles, Met. 1050a 5-30.

11 Aristóteles, Met. 1050a 5-30.

12 Enciclopedia Encarta, 2000.

13 Alkire, 2001.

14 Maslow, 1991: 23.

15 Maslow, 1991: 23.

16 Capacidad de vivir hasta el final una vida de duración normal, no muriendo prematuramente o que la vida esté tan menoscabada que no tenga ningún valor seguir viviendo. Capacidad de buena salud, incluyendo la nutrición y la salud reproductora.

17 Bienestar material: teniendo suficiente comida, recursos y trabajo.

18 La vida misma: su mantenimiento y reproducción, la salud.

19 Nutrición, comida, agua, vivienda, salud, medio ambiente.

20 Maslow, 1991: 25

21 Integridad corporal, libertad de movimiento de un lugar a otro, teniendo soberanía sobre los límites corporales de uno mismo, seguridad contra agresiones, incluso el asalto sexual, el abuso sexual infantil, la violencia doméstica; teniendo oportunidades para la satisfacción sexual y la opción en materias de reproducción.

22 Seguridad, paz civil, físicamente a salvo, medio ambiente seguro, legalidad y acceso a la justicia, seguridad del adulto mayor, confianza en el futuro.

23 Seguridad para la niñez, seguridad física, seguridad económica, maternidad y nacimientos seguros. 
24 Seguridad, armonía y estabilidad de la sociedad, de las relaciones y de uno mismo.

25 Maslow, 1991: 29.

26 Capacidad de afiliación, pudiendo vivir para y hacia otros, reconociendo y mostrando preocupación por otros seres humanos, comprometido en las múltiples formas de interacción social, imaginando la situación del otro y teniendo compasión por ella, con capacidad para la justicia y la amistad, defendiendo la institucionalidad de las formas de afiliación, las libertades de asamblea y de discurso político.

Teniendo las bases sociales del respeto mutuo y la no humillación, pudiendo recibir un trato digno cuyo valor es igual al de otros, que implica protección frente a la discriminación en base a la raza, sexo, religión, casta, etnicidad u origen nacional.

27 Bienestar social, cuidado familiar, respeto, dignidad, paz, armonía y buenas relaciones en la comunidad.

28 Razones básicas para la acción: la amistad, las variadas formas de armonía entre los individuos y los grupos, viviendo en paz unos con otros en vecindad $y$ amistad.

29 Marx, 1969: 188.

30 Maslow, 1991: 29 .

31 Bienestar psicológico, paz espiritual, felicidad, armonía.

32 Capacidad emocionales, pudiendo tener lazos con las cosas y con las personas, para amar y extrañar la ausencia de los seres queridos. No teniendo el desarrollo emocional destruido por el miedo y la ansiedad, por el abuso o el abandono.

33 Maslow, 1991: 33.

34 Maslow, 1991: 37.

35 Razones básicas para la acción en el conocimiento y la experiencia estética.

36 Capacidad para sentir, imaginar, pensar y razonar.

37 Nietzsche, 1989: 237-240.

38 Maslow, 1991: 32

9 Maslow, 1991: 203

Maslow, 1991: 213.

1 Sen, 1984: 323.

42 Maslow, 1991: 219.

43 Maslow, 1991: 217.

44 Peña, 1996: 142-143.

45 Peña, 1996: 149.

46 Peña, 1996: 157.

47 Aristóteles. «Ética a Nicómaco». Libro 1ro. Capítulo VII. Los Clásicos, Obras filosóficas de Aristóteles. México, Editorial W. M. Jackson Inc., 1973.

\section{BIBLIOGRAFÍA}

Alkire, S. Dimensions of Human Development. Washington World Bank, Poverty Reduction Group, 2001.

Aristóteles. La Metafísica. España, Editorial Gredos, 1998.

Banco Mundial. World development report. 2000/ 2001 .

Banco Mundial. http://lnweb18.worldbank.org/news/ pressrelease.nsf/AttachmenTs/pr042002-es.pdf/ \$File/pr042002-es.pdf, 2002.
CEPAL. Panorama Social de América Latina y el Caribe. 2002/2003.

Figueroa, A. Teorías Económicas del Capitalismo. Lima, PUCP Fondo Editorial, 2001.

Figueroa, A. Ciencia y desarrollo, el papel de la ciencia económica. Documento N. ${ }^{\circ} 202$. Cisepa PUCP, 2001

Habermas, J. Teoría de la Acción Comunicativa. Madrid, Ediciones Taurus, 1988.

Hegel, G. W. F. Fenomenología del espíritu. México, Fondo de Cultura Económica. 1998.

Iguiñiz, J. La pobreza es multidimensional, un ensayo de clasificación. Inédito PUCP.

Iguiñiz, J. «Ética y Desarrollo: Enfoques y Realidad Mundial y Latinoamericana». Ponencia presentada en el III Simposio Ética, Política y Economía: Entre la Globalización y la Pobreza. Quito, 15 de setiembre de 2004 .

Marx, K. Obras Escogidas, Moscú, Editorial Progreso, 1969

Marx,K. El Capital, crítica de la Economía Política. México, Ediciones Siglo XXI, 1984.

Maslow, Abraham. Motivación y personalidad. España, Ediciones Díaz de Santos S. A., 1991.

Microsoft Encarta. Enciclopedia Microsoft Corporation, 2000.

Mill, J. S. El utilitarismo. Buenos Aires, Ediciones Aguilar, 1974.

Nietzsche, F. El nacimiento de la tragedia. España, Alianza Editorial, 1989.

Nussbaum, M. La calidad de vida. México, Fondo de Cultura Económica, 1996.

Peña Cabrera, A. Racionalidad Occidental y Racionalidad Andina: Una comparación. Cusco, Ediciones Bartolomé de las Casas, 1996.

PNUD. Informe sobre Desarrollo Humano, 1998.

Rawls, J. Teoría de la Justicia. México, Fondo de Cultura Económica, 1997

Rawls, J. Justicia como equidad. Madrid, Ediciones Tecnos, 1999.

Samuelson, P. A. Curso de Economía Moderna. España, Ediciones Aguilar, 1968.

Sen, A. Resources, Values and Development. Massachussets, Harvard University Press, 1984 . 
Sen, A. Nuevo Examen de la Desigualdad. Madrid, Alianza, 1995.

Sen, A. Desarrollo y libertad. México, Ediciones Planeta, 2000.

Sen, A. El nivel de vida. Madrid, Editorial Complutense, 2001.
Valls Plana, R. Del Yo al nosotros. México, Fondo de Cultura Económica, 1985.

Varian, H. Microeconomía Intermedia, un enfoque moderno. Editor Antoni Bosch, España, 1994 . 
